Article

\title{
Physiological Characterization of a Novel Wild-Type Yarrowia lipolytica Strain Grown on Glycerol: Effects of Cultivation Conditions and Mode on Polyols and Citric Acid Production
}

\author{
Seraphim Papanikolaou ${ }^{1,2, *}$, Panagiota Diamantopoulou ${ }^{3}$, Fabrice Blanchard ${ }^{2}$, \\ Eleni Lambrinea $^{3}$, Isabelle Chevalot ${ }^{2} \oplus$, Nikolaos G. Stoforos ${ }^{1}$ and Emmanuel Rondags ${ }^{2, *}$ \\ 1 Department of Food Science and Human Nutrition, Agricultural University of Athens, 75 Iera Odos, \\ 11855 Athens, Greece; stoforos@aua.gr \\ 2 Laboratoire Réactions Génie des Procédés (LRGP-CNRS UMR 7274), Université de Lorraine, 2 Avenue de la \\ Forêt de Haye, 54518 Vandoeuvre-lès-Nancy, France; fabrice.blanchard@univ-lorraine.fr (F.B.); \\ isabelle.chevalot@univ-lorraine.fr (I.C.) \\ 3 Institute of Technology of Agricultural Products (ITAP), Hellenic Agricultural Organization-Demeter, \\ 1 Sofokli Venizelou Street, 14123 Lykovryssi, Greece; pdiamantopoulou@itap.com.gr (P.D.); \\ labitap.elgo@gmail.com (E.L.) \\ * Correspondence: spapanik@aua.gr (S.P.); emmanuel.rondags@univ-lorraine.fr (E.R.)
}

Received: 16 September 2020; Accepted: 12 October 2020; Published: 21 October 2020

\begin{abstract}
A new yeast wild-type Yarrowia lipolytica isolate presented efficient growth on glycerol. During flask cultures, nitrogen limitation led to the secretion of sugar-alcohols as the major metabolites of the process (mannitol, arabitol and erythritol), whereas insignificant quantities of citrate were synthesized. Although in some instances high initial glycerol concentrations were employed $(\approx 150 \mathrm{~g} / \mathrm{L})$, remarkable glycerol assimilation and polyol secretion was observed. Total polyols $\approx 52 \mathrm{~g} / \mathrm{L}$ (conversion yield on glycerol consumed $=0.43 \mathrm{~g} / \mathrm{g}$ ) was recorded in the flask experiments. The sugar-alcohol production bioprocess was successfully simulated with the aid of a modified Velhlust-Aggelis model that fitted very well with the experimental data, while optimized parameter values seemed to be quite consistent. In bioreactor trials, a noticeable metabolic shift towards citric acid production was observed, while simultaneously insignificant polyol quantities were produced. In fed-batch bioreactor experiments, a total citric acid quantity $\approx 102 \mathrm{~g} / \mathrm{L}$ was recorded-one of the highest in the literature for wild-type Y. lipolytica strains. This metabolic transition was due to higher oxygen saturation into the medium that occurred in the bioreactor experiments compared with the flasks. Cellular lipids produced in the bioreactor trial contained higher concentrations of unsaturated fatty acids compared with those produced in flasks.
\end{abstract}

Keywords: citric acid; erythritol; glycerol; mannitol; sugar-alcohols; Yarrowia lipolytica

\section{Introduction}

The constant and continuous decrease in non-renewable energy feedstocks and the concomitant rise in the price of crude oil have resulted in the increment of scientific interest concerning the discovery and study of "renewable" types of energy sources. Biodiesel (viz. alky-esters of fatty acids esterified with low-molecular weight alcohols) and bioethanol are considered as the most important and interesting types of biofuels [1-5]. The synthesis of the above-mentioned biofuels is connected with the production of concentrated glycerol-containing waters, which are the principal side-products of these processes. Moreover, besides bioethanol production, important quantities of glycerol-containing 
water can also be generated as side products in various alcoholic beverages' production facilities; for instance, during the typical ethanol fermentation process, ethanol is separated via distillation. The liquid fraction of the remaining material (the so-called "thin stillage") contains c. $2 \% w / v$ of glycerol [6]. Additionally, liquid waste streams containing relatively elevated levels of glycerol are generated in the various oleochemical facilities employing transformations of vegetable or animal fats (i.e., soap-production facilities) [2,3]. Finally, even larger quantities of glycerol-containing water can be envisaged to be generated into the near future, due to the very high intra-cellular accumulation of glycerol as a storage material (in quantities up to $c .85 \% w / w$ ) in several algal species like Dunaliella sp. In some of the above-mentioned cases, quantities of glycerol in water reaching levels up to $7.8 \mathrm{M}$ (equivalent to $c .720 \mathrm{~g}$ of glycerol per L of water) may be generated [7].

This entire situation has inevitably negatively affected the price of glycerol feedstocks in the market volume, which presents a constant decrease. In 2007, a landmark year for the process of biodiesel production, in several EU countries including but not limited to Germany, concentrated glycerol-containing water derived from the biodiesel manufacture process, was considered as a "typical industrial waste-water". Its price was $c .0 .0 \mathrm{USD} / \mathrm{kg}$ (as opposed to pure glycerol which presented a price of $c$. $1.20 \mathrm{USD} / \mathrm{kg}$ that year). Thus, crude glycerol was employed only for biogas production [8]. In the years that followed, the situation has been relatively ameliorated by taking into consideration both the price and the processes of the purification of glycerol; especially in countries with an advanced technological and scientific level, the industrial production of biodiesel was accompanied (and is currently accompanied) by the side production of relatively highly purified industrial glycerol feedstocks (e.g., purity of $\approx 85-90 \% w / w$, sometimes $>90 \% w / w$ ). This feedstock can be used directly as the starting material for the chemical synthesis of epichlorohydrin or it can be used in various pharmaceutical applications after further purification processes are carried out [1,4].

In any case though, the appearance of glycerol as a side-product in the various agro-food, biofuel and industrial activities mentioned above, is constantly rising. Therefore, the conversion of this low-value compound into several types of biotechnological products currently attracts enormous attention $[3-5,9,10]$. Wild-type, mutant (i.e., acetate negative ones) and genetically engineered strains of the non-conventional polymorphic yeast Yarrowia (synonyms: Candida_Saccharomycopsis—Endomycopsis) lipolytica have been successfully used in recent years as microbial cell factories, amenable to convert glycerol into a plethora of valuable interesting compounds, including but not limited to microbial oils, organic acids (i.e., citric acid, succinic acid, acetic acid), yeast mass, sugar alcohols (i.e., mannitol, erythritol, arabitol), etc. [3,10-15].

Recent investigations by our research team have indicated that after an initial screening study, a wild-type novel isolate of the non-conventional polymorphic yeast $Y$. lipolytica, namely strain LMBF-Y46, has been revealed as being capable to produce amounts of polyols (mainly mannitol), during a screening study in shake-flask experiments on biodiesel-derived glycerol [16]. It was decided to further quantitatively study the physiological behavior of the above-mentioned strain, using a nitrogen-limited media based on crude or pure glycerol, and also in cultures with increased initial concentrations of glycerol, in shake flasks. Moreover, a scaled-up laboratory-scale stirred tank bioreactor production system was produced. Considerations concerning the yeast physiological behavior were comprehensively assessed and discussed.

\section{Materials and Methods}

\subsection{Microorganism, Media and Culture Conditions}

The yeast strain used in the current study was a new indigenous wild-type Y. lipolytica strain, coded LMBF Y-46, isolated from gilt-head (sea) bream (Sparus aurata) fish [17], having been previously demonstrated as capable of producing significant amounts of yeast biomass and mannitol in a first screening-type study [16]. The maintenance of the strain as well as the salt composition of the basal medium used for the fermentations, have both previously been described $[18,19]$. The nitrogen sources 
employed were $\left(\mathrm{NH}_{4}\right)_{2} \mathrm{SO}_{4}$ (containing c. $21 \%$, w/w, of nitrogen) and yeast extract (containing $c$. $7 \%, w / w$, of nitrogen and c. $8 \%, w / w$, of carbon). Initially $\left(\mathrm{NH}_{4}\right)_{2} \mathrm{SO}_{4}$ at $1.5 \mathrm{~g} / \mathrm{L}$ and yeast extract at $1.0 \mathrm{~g} / \mathrm{L}$ were employed; at this stage, a relatively low initial glycerol concentration (Gly $)_{0}$ was employed $(\approx 40 \mathrm{~g} / \mathrm{L})$. Thereafter, and in order to enhance the production of yeast biomass, in addition to potentially enhancing glycerol assimilation, higher initial nitrogen concentrations were employed; in this second set of cultures, $\left(\mathrm{NH}_{4}\right)_{2} \mathrm{SO}_{4}$ at an initial concentration of $2.0 \mathrm{~g} / \mathrm{L}$ and yeast extract at an initial concentration of $3.0 \mathrm{~g} / \mathrm{L}$ were employed [18]. Additionally, higher initial concentrations of glycerol were used (up to $c .150 \mathrm{~g} / \mathrm{L}$ ). The carbon sources used in all trials were either industrial (biodiesel-derived) crude glycerol (Agroinvest SA; Achladi, Fthiotis prefecture, Greece) with a purity of $c .81 \% w / w$ [18] or pure glycerol (Prolabo Chemicals, Fontenaysous bois, France, purity c. $98 \% w / w$ ). The impurities in industrial glycerol were composed of $11-12 \% w / w$ water, $5-6 \% w / w$ potassium salts, $1 \% w / w$ free-fatty acids and $<0.2 \% w / w$ methanol. The initial $\mathrm{pH}$ of all media was $6.0 \pm 0.1$.

Shake-flask trials were conducted batch-wise in Erlenmeyer non-baffled flasks of $250 \mathrm{~mL}$ filled with $50 \pm 1 \mathrm{~mL}$ of culture medium, previously sterilized (at $T=115^{\circ} \mathrm{C} ; 20 \mathrm{~min}$ ) and inoculated with $1 \mathrm{~mL}$ of exponential pre-culture containing $1-3 \times 10^{6}$ cells (the initial cell mass concentration $-X_{0}$ was $\approx 0.10 \mathrm{~g} / \mathrm{L}$ ) $[18,19]$. The pre-culture was carried out in liquid-modified YPD medium, in which dextrose had been replaced by glycerol (the pre-culture medium contained yeast extract at $10.0 \mathrm{~g} / \mathrm{L}$, peptone at $10.0 \mathrm{~g} / \mathrm{L}$ and pure glycerol at $20.0 \mathrm{~g} / \mathrm{L}$ ). Pre-cultures were incubated in an orbital shaker (for $24 \pm 2 \mathrm{~h}$ at $180 \pm 5 \mathrm{rpm}, T=28 \pm 1{ }^{\circ} \mathrm{C}$ ) after inoculation of a loop by a freshly prepared slant of the strain. After inoculation by the pre-culture, flasks were incubated at $T=28 \pm 1{ }^{\circ} \mathrm{C}$ at $180 \pm 5 \mathrm{rpm}$ in a rotary shaker (New Brunswick Innova 43 Incubator Shaker; NH, USA). In the experiments performed in shake-flask mode, a constant drop in the $\mathrm{pH}$ value of the medium was observed throughout the culture time, and the $\mathrm{pH}$ value was always maintained in the flasks at values of $\geq 4.5 \pm 0.1$ by aseptically adding $2 \mathrm{M} \mathrm{NaOH}$ (for more details see: Papanikolaou et al. [19]). In most of the culture steps and for most of the shake-flask experiments performed, the medium $\mathrm{pH}$ remained at $>4.8$, being found within the range 4.8-5.8.

Batch and pulsed fed-batch bioreactor experiments were also performed, in a bench-top $3 \mathrm{~L}$ bioreactor (Applikon Biotechnology; Delft, The Netherlands), containing 1.9 L of previously sterilized fermentation medium (at $T=115^{\circ} \mathrm{C} ; 45 \mathrm{~min}$ ) and inoculated with $100 \mathrm{~mL}$ of 24 h exponential Y. lipolytica pre-culture (see previously for the pre-culture details). Culture conditions in the bioreactor experiments were as in Papanikolaou et al. [18]: incubation temperature $T=28 \pm 1^{\circ} \mathrm{C}$; agitation $=800 \pm 5 \mathrm{rpm}$; aeration set between 0.1 and $2.0 \mathrm{vvm}$ in order to maintain a dissolved oxygen tension (DOT) in the vessel above $20 \%$, during all culture phases, thus full aerated conditions were imposed (see Palaiogeorgou et al. [20]); $\mathrm{pH}=6.0 \pm 0.2$ regulated with automatic addition of concentrated $\mathrm{NaOH}$ (5 M). For the pulsed fed-batch bioreactor experiment, pulses of concentrated and previously sterilized glycerol quantities were added into the vessel at various incubation times, and all fermentation parameters were the same as in the batch bioreactor trial.

\subsection{Analyses}

In order to proceed to the various analyses, the whole content of the flasks $(\approx 46-48 \mathrm{~mL})$ or a sample $\approx 20 \mathrm{~mL}$ of the bioreactor experiments was collected. In the case of the shake-flask trials, due to slight water evaporation, the volume of the liquid medium in the flasks after harvesting was $47 \pm 1 \mathrm{~mL}$. Certainly, the more the culture duration was elevated, the more water evaporation of the medium occurred. Nevertheless, the volume of the medium was never lower than $46 \mathrm{~mL}$. This volume was always corrected to $50 \mathrm{~mL}$ and the whole content of the flask was used in the performed analyses. Regardless of the volume of the sample, yeast cells were harvested by centrifugation, and yeast total biomass quantity was determined through its dry cell weight (DCW, g/L) [16,21]. Non-consumed glycerol (Gly), citric acids (citric + iso-citric acid) (CA), mannitol (Ml), arabitol (Ara) and erythritol (Ery) were determined with the aid of HPLC analysis [18,22]. In several fermentation points, iso-citric was assayed according to Papanikolaou et al. [23]. Cellular lipids were extracted from the yeast DCW 
according to the modified "Folch" method [16,24], while total microbial oil was recovered and trans-esterified according to Gardeli et al. [24]. The produced fatty acid methyl-esters (FAMEs) were suspended in hexane and analyzed by GC analysis in a Varian CP-3800 chromatograph equipped with flame ionization detector (Agilent Technologies, Santa Clara, CA, USA), in which an Agilent J\&W Scientific DB23 capillary column (model n.123-2332, $30.0 \mathrm{~m} \times 0.32 \mathrm{~mm}$, film thickness $0.25 \mu \mathrm{m}$ ) (Agilent Technologies, Santa Clara, CA, USA) was used. Helium gas was used as a carrier gas with a column flow rate of $2.0 \mathrm{~mL} / \mathrm{min}$. The set up conditions were as follows: initial oven temperature was set at $T=150^{\circ} \mathrm{C}$, held for $18 \mathrm{~min}$, subsequently rammed to $T=185^{\circ} \mathrm{C}$ at a rate of $5^{\circ} \mathrm{C} / \mathrm{min}$ and held for $2 \mathrm{~min}$. Then the oven temperature was moved to $T=210^{\circ} \mathrm{C}$ at a flow rate of $5^{\circ} \mathrm{C} / \mathrm{min}$ and held for $2 \mathrm{~min}$, then increased to $\mathrm{T}=240^{\circ} \mathrm{C}$ at $10^{\circ} \mathrm{C} / \mathrm{min}$. The injector and flame ionization detector temperatures were set at $T=260^{\circ} \mathrm{C}$ and $T=270{ }^{\circ} \mathrm{C}$, respectively. Individual FAMEs were identified by comparison of their retention times with external standard (Supelco 37 Component FAME Mix, CRM47885) retention times. The amounts of individual FAMEs identified were expressed in $\%$ of the total fatty acid areas chromatograms identified.

In the case of the shake-flask cultures and for various fermentation points, the DOT was determined according to the procedure proposed in Palaiogeorgou et al. [20]. In all of the cases in which DOT was measured (measurements were conducted at the phase in which polyols were accumulated into the medium), and for all of the Gly quantities set into the medium, DOT values were between $20 \%$ and $50 \% \mathrm{v} / \mathrm{v}$. Moreover, in several of the shake-flask cultures performed, ammonium ion concentration into the medium was determined with an ammonium selective electrode (SA 720, Orion; USA), according to previously indicated procedure [25].

In all the kinetic experiments both in shake-flask and bioreactor trials, each experimental point presented in the figures and the tables is the mean value of two measurements deriving from two independent experiments (SE in most of the experimental points was $\leq 18 \%$ ).

Nomenclature: X: Biomass concentration (dry cell weight-DCW, g/L); Gly: Glycerol concentration $(\mathrm{g} / \mathrm{L}) ;$ : reaction time (h); $C A$ : Citric acids (citric + iso-citric acid) concentration (g/L); Ml: Mannitol concentration $(\mathrm{g} / \mathrm{L})$; Ara: Arabitol concentration $(\mathrm{g} / \mathrm{L})$; Ery: Erythritol concentration $(\mathrm{g} / \mathrm{L})$; Pol: Total polyols concentration $(\mathrm{g} / \mathrm{L}) ; q_{P o l}$ : specific polyols formation rate, $\mathrm{g}$ of polyols per $\mathrm{g}$ of biomass per $\mathrm{h}$; $Y_{P o l / G l y}:$ yield coefficient for total polyols production with respect to glycerol consumed, $\mathrm{g}_{\mathrm{Pol}} / \mathrm{g}_{\mathrm{Gly}}$ (g of total polyols produced per g of glycerol consumed); $Y_{C A / G l y}$ : yield coefficient for citric acid production with respect to glycerol consumed, $\mathrm{g}_{\mathrm{CA}} / \mathrm{g}_{\mathrm{Gly}}$ ( $\mathrm{g}$ of citric acid produced per $\mathrm{g}$ of glycerol consumed); $Y_{X / G l y}$ : yield coefficient for DCW production with respect to glycerol consumed, $g_{X} / g_{G l y}$ (g of DCW produced per $\mathrm{g}$ of glycerol consumed); $\mathrm{r}_{\mathrm{CA}}$ : rate of citric acid production ( $\mathrm{g}_{\mathrm{CA}}$ per $\mathrm{L}$ per $\mathrm{h}$ ); $\mathrm{r}_{\mathrm{Gly}}$ : rate of glycerol consumption ( $g_{G l y}$ per L per $h$ ); $r_{X}$ : rate of biomass production ( $g_{X}$ per $L$ per $h$ ); $\mu$ : specific biomass production rate $\left(\mathrm{h}^{-1}\right)$, calculated in batch cultures by the formula $\mu_{\max }=\frac{\ln \left(\frac{X_{1}}{X_{0}}\right)}{t_{1}-t_{0}}$ where $X_{1}$ was the first experimental point after inoculation and $t_{1}$ was the respective time; $X_{0}$ was the initial DCW quantity and $t_{0}=0 \mathrm{~h} ; P_{C A}$ : Citric acids volumetric productivity (gCA per L per h); indexes 0 and cons refer to the initial and the consumed quantity of the elements in the experiments carried out; index max refers to the maximum value of a particular parameter in the cultures.

\section{Results and Discussion}

3.1. Metabolic Characterization of Yarrowia lipolytica LMBF Y-46: Effect of Different Glycerol Sources under Nitrogen Limitation

In the first part of this report, it was desirable to evaluate the performances of Y. lipolytica LMBF Y-46 in shake-flask experiments in media in which pure or crude glycerol ( $G l y_{0} \approx 40 \mathrm{~g} / \mathrm{L}$ ) had been employed. Initial nitrogen concentration used in the medium was $\left(\mathrm{NH}_{4}\right)_{2} \mathrm{SO}_{4}$ at $1.5 \mathrm{~g} / \mathrm{L}$ and yeast extract at $1.0 \mathrm{~g} / \mathrm{L}$ (initial molar ratio $\approx 48$ moles/moles). The kinetics of both experiments are shown in Figure 1a-d. For both cases, DCW production almost reached a plateau $(X=10-11 \mathrm{~g} / \mathrm{L})$ at $t=120 \mathrm{~h}$ after inoculation. Onset of the secretion of polyols had been given earlier $(t \approx 50-55 \mathrm{~h}$ 
after inoculation). At the very same fermentation step ( $t \approx 50-55 \mathrm{~h}$ after inoculation) ammonium nitrogen had barely disappeared from the growth medium (initial $\mathrm{NH}_{4}{ }^{+}$concentration $\approx 400 \mathrm{mg} / \mathrm{L}$, $\mathrm{NH}_{4}{ }^{+}$concentration at $t \geq 50-55 \mathrm{~h}$ after inoculation $\approx 25 \pm 10 \mathrm{mg} / \mathrm{L}$ ). Thus, after that given fermentation point, cultures were performed under nitrogen-limited conditions, providing evidence that the onset of the accumulation of polyols into the medium occured after nitrogen had been depleted from the medium. $X_{\max }$ concentration was slightly higher in the case of pure glycerol compared with the raw feedstock (11.2 vs. $10.5 \mathrm{~g} / \mathrm{L}$; see Figure 1a). The maximum quantity of polyols produced in this set of experiments was c. $13.5 \mathrm{~g} / \mathrm{L}$ irrespective of the use of crude or pure glycerol. Mannitol was the principal polyol synthesized (c. $80-84 \% w / w$ of the Pol synthesized) whereas, other polyols that were synthesized, in notably lower quantities, were erythritol and to lesser extent arabitol. For both experiments, polyols were re-consumed at the late culture steps, when glycerol concentration into the medium presented essentially low concentrations (Figure 1b,c).

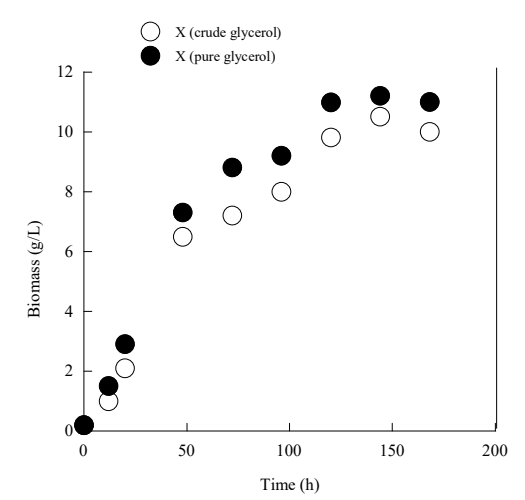

(a)

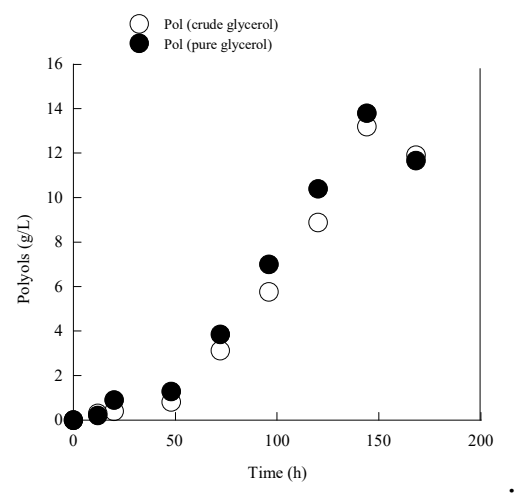

(c)

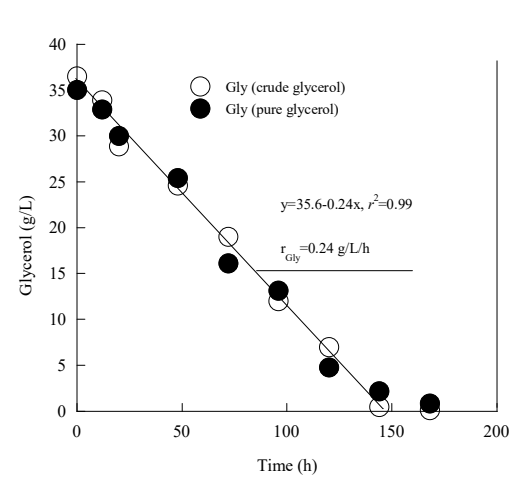

(b)

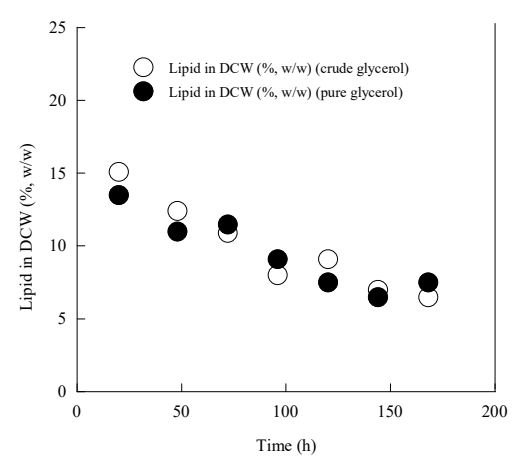

(d)

Figure 1. Kinetics of dry yeast cell mass production $(X, \mathrm{~g} / \mathrm{L})(\mathbf{a})$, glycerol assimilation $(G l y, \mathrm{~g} / \mathrm{L})(\mathbf{b})$, total polyols synthesis $(\mathrm{Pol}, \mathrm{g} / \mathrm{L})$ and $(\mathrm{c})$ lipid in dry cell weight $(\%, w / w),(\mathbf{d})$ by Yarrowia lipolytica LMBF Y-46, during growth on pure and biodiesel-derived glycerol in shake-flask experiments under nitrogen-limited conditions. Culture conditions: growth in $250 \mathrm{~mL}$ conical flasks at $180 \pm 5 \mathrm{rpm}$, initial $\mathrm{pH}=6.0 \pm 0.1$, $\mathrm{pH}$ ranging between 4.5 and 6.1, incubation temperature $T=28 \pm 1^{\circ} \mathrm{C}$. Each experimental point is the mean value of two independent determinations ( $\mathrm{SE} \leq 18 \%$ ).

The assimilation of glycerol for both trials was almost linear (see kinetics of remaining into the medium glycerol in Figure $1 \mathrm{~b}$ ) and the rate of glycerol consumption $\left(\mathrm{r}_{\mathrm{Gly}}\right)$, calculated after linear regression of the experimental data of remaining in the medium glycerol vs. time for both trials, seemed unaffected by the utilization of the pure or the crude substrate. For both fermentations, $\mathrm{r}_{\mathrm{Gly}}$ was $=0.24 \mathrm{~g} / \mathrm{L} / \mathrm{h}$ (Figure $1 \mathrm{~b}$ ). This result, together with the observations concerning the production of polyols and DCW that seemed not to differ between the two fermentations carried out, indicate that the impurities of the substrate did not seem to have any important impact upon the physiological 
behavior of the strain. In agreement with these results, for a number of wild-type microbial strains (i.e., Klebsiella oxytoca, Mortierella ramanniana, some strains of the species Y. lipolytica) cultivated on glycerol deriving from various origins, the impurities of the feedstock did not seem to have any impact upon the physiological behavior of the mentioned microorganisms [22,23,26,27]. In contrast, in other cases (i.e., Clostridium butyricum, C. pasteurianum, Meyerozyma caribbica, Rhodotorula minuta, other strains belonging to the species Y. lipolytica, etc.), glycerol impurities seemed to (drastically) modify the cellular metabolism of the implicated microorganisms [28-34]. Therefore, the impurities found in the crude glycerol feedstock did not seem to have a clear positive or negative effect upon the production of dry yeast biomass and metabolites by Y. lipolytica yeast. However, in some cases it must be pointed out that the impurities found in the medium seemed to enhance the production of the metabolites by various yeast strains including Y. lipolytica [29,32-34]. From the above-mentioned analysis, therefore, it seems that the biosynthesis of metabolites by Y. lipolytica strains cultivated on glycerol, appears to be strain dependent in relation to the origin of the feedstock implicated in the bioprocess performed.

According to theory, polyols are synthesized as secondary anabolic compounds with their biosynthesis being coupled with nitrogen limitations in the growth medium [3,10,13-15,35-37]. Though, the current investigation, as well as other limitations in the literature $[18,21]$ indicate that the total biomass biosynthesis may occur simultaneously with the biosynthesis of polyols into the medium. In fact, in the current investigation it was seen that typically after nitrogen depletion from the medium (at $t \approx 50-55 \mathrm{~h}$ after inoculation), polyols were secreted, while an almost linear profile of polyols biosynthesis occurred between 50 and $150 \mathrm{~h}$ after inoculation (see Figure $1 \mathrm{c}$ ). On the other hand, in spite of nitrogen depletion that, as stated occurred at $t \approx 50-55 \mathrm{~h}$ after inoculation (at that fermentation step $X$ concentration was $\approx 7.0 \mathrm{~g} / \mathrm{L}$ ), some supplementary biomass production occurred between $50-55 \mathrm{~h}$ and $t=120 \mathrm{~h}$ after inoculation; as indicated, DCW production plateaued at $t=120 \mathrm{~h}$, and when biomass concentration reached its plateau $X$ concentration was $\approx 10-11 \mathrm{~g} / \mathrm{L}$. This supplementary total biomass production that occurred at the late growth stages did not indicate that cells "fattened" as fermentation proceeded; in fact, insignificant quantities of total lipids were accumulated inside the yeast cells for both trials performed, despite the fact that cultures were performed under nitrogen limitation (Figure 1d). The kinetic results of the current investigation indicate that somehow elevated lipid quantities were synthesized at the relatively early growth stage of the culture, with lipid in DCW values decreasing as the fermentation proceeded (Figure 1d) This is in accordance with various literature reports in which Y. lipolytica strains (wild-type or mutant ones) had been cultured batch-wise in glycerol-based media $[18,38-40]$. The total dry biomass production increase that occurred after nitrogen had been depleted from the culture (viz. between $50-55 \mathrm{~h}$ and $150 \mathrm{~h}$ after inoculation), could suggest the accumulation of intra-cellular polysaccharides inside the cells occurring after nitrogen deprivation from the medium. This assumption is in accordance with the reports of several microorganisms like other Y. lipolytica strains or other yeast species/genera like Apiotrichum curvatum, Rhodosporidium toruloides, Metschnikowia sp. [16,37,41-43].

\subsection{Metabolic Characterization of Yarrowia lipolytica LMBF Y-46: Effect of Glycerol Concentration in Media with Constant Initial Nitrogen in Shake-Flask Trials}

In the next approach, and in order to more profoundly quantify the metabolism of Y. lipolytica LMBF Y-46, another set of shake-flask cultures was carried out. In this set, a higher initial nitrogen concentration was set into the medium (ammonium sulfate and yeast extract at an initial concentration of 2.0 and $3.0 \mathrm{~g} / \mathrm{L}$, respectively) in order to further "boost" the production of the total biomass, and potentially to increase the consumption rate of glycerol. Variable Gly concentrations with higher initial substrate quantities than the previous experiment, were tested ( $G l y_{0}$ quantities adjusted between $\approx 70$ and $\approx 150 \mathrm{~g} / \mathrm{L}$ ). It was also decided to utilize the pure substrate as a carbon source (pure glycerol therefore was employed instead of crude). This decision was taken in order to ascertain that all potential changes observed in the quantitative cellular metabolism in these experiments were due only to the increment in $G l y_{0}$ concentration (and also to the increase in the initial $\mathrm{C} / \mathrm{N}$ ratio) employed 
into the medium and not to the potential accumulation of crude glycerol impurities into the medium, specifically at the higher $G l y_{0}$ concentrations imposed. The obtained results of this set of experiments are shown in Table 1. As was anticipated, higher total DCW quantities were produced when compared with the previous experiment, since increased initial nitrogen concentrations were employed in the former case. Likewise, glycerol consumption was equally linear for this series of trials; linear regression of the experimental data of remaining glycerol concentration vs. incubation time for the points in which non-negligible glycerol quantity remained unconsumed into the medium, revealed a glycerol consumption rate value $\left(\mathrm{r}_{\mathrm{Gly}}, \mathrm{g} / \mathrm{L} / \mathrm{h}\right)$ (see also Section 3.1). This value noticeably decreased as the Gly $y_{0}$ concentration increased in the medium. However, the $\mathrm{r}_{\mathrm{Gly}}$ value was always higher than in the previous set of experiments in which a lower initial nitrogen concentration was employed; in all trials and irrespective of the Gly concentration in the medium, linear regression of the remaining glycerol $(G l y) f(t)$ revealed an $r^{2}$ value $\geq 0.95$ (linear regressions not presented) providing evidence of the linearity of consumption of glycerol by $Y$. lipolytica, with $\mathrm{r}_{\mathrm{Gly}}$ ranging between $0.54 \mathrm{~g} / \mathrm{L} / \mathrm{h}\left(G l y_{0} \approx 70 \mathrm{~g} / \mathrm{L}\right)$ and $0.37 \mathrm{~g} / \mathrm{L} / \mathrm{h}\left(G l y_{0} \approx 150 \mathrm{~g} / \mathrm{L}\right)$.

Table 1. Quantitative data of cultures of Yarrowia lipolytica LMBF Y-46 on glycerol-based media in which various initial glycerol concentrations $\left(G l y_{0}\right)$ were added with nitrogen being added to the medium as ammonium sulfate $(2.0 \mathrm{~g} / \mathrm{L})$ and yeast extract $(3.0 \mathrm{~g} / \mathrm{L})$. Culture conditions: growth in $250 \mathrm{~mL}$ conical flasks (at $180 \mathrm{rpm}$, initial $\mathrm{pH}=6.0 \pm 0.1, \mathrm{pH}$ ranging between 4.4 and 6.1, incubation temperature $\left.T=28 \pm 1{ }^{\circ} \mathrm{C}\right)$. Culture details when the maximum concentration of mannitol (Ml, g/L) (a), erythritol (Ery, g/L) (b), arabitol (Ara, g/L) (c) and yeast dry cell biomass (X, g/L) (d) was achieved. $\mathrm{Pol}$ is the sum of polyols (in $\mathrm{g} / \mathrm{L}$ ) at the given fermentation times. Each experimental point presented is the mean value of two independent determinations.

\begin{tabular}{ccccccccccc}
\hline $\begin{array}{c}\text { Gly } \\
(\mathrm{g} / \mathrm{L})\end{array}$ & & $\begin{array}{c}\text { Time } \\
(\mathbf{h})\end{array}$ & $\begin{array}{c}\text { Glycons } \\
(\mathrm{g} / \mathrm{L})\end{array}$ & $\begin{array}{c}\mathrm{r}_{\mathrm{Gly}} \\
(\mathrm{g} / \mathrm{L} / \mathbf{h})\end{array}$ & $\begin{array}{c}\boldsymbol{X} \\
(\mathrm{g} / \mathrm{L})\end{array}$ & $\begin{array}{c}\text { Ml } \\
(\mathrm{g} / \mathrm{L})\end{array}$ & $\begin{array}{c}\text { Ery } \\
(\mathrm{g} / \mathrm{L})\end{array}$ & $\begin{array}{c}\text { Ara } \\
(\mathrm{g} / \mathrm{L})\end{array}$ & $\begin{array}{c}\boldsymbol{P} \text { ol } \\
(\mathrm{g} / \mathrm{L})\end{array}$ & $\begin{array}{c}Y_{P o l / G l y} \\
(\mathrm{~g} / \mathbf{g})\end{array}$ \\
\hline$\approx 70$ & $\mathrm{a}, \mathrm{b}, \mathrm{c}$ & 134 & $65.0 \pm 4.5$ & 0.54 & $16.1 \pm 1.5$ & $9.2 \pm 1.4$ & $7.3 \pm 1.2$ & $4.1 \pm 0.7$ & $20.6 \pm 3.3$ & 0.32 \\
& $\mathrm{~d}$ & 183 & $65.6 \pm 3.9$ & & $22.4 \pm 2.0$ & $6.1 \pm 0.8$ & $3.1 \pm 0.6$ & $1.9 \pm 0.4$ & $11.1 \pm 1.8$ & 0.17 \\
\hline$\approx 100$ & $\mathrm{a}, \mathrm{b}, \mathrm{c}, \mathrm{d}$ & 183 & $95.4 \pm 7.1$ & 0.52 & $15.0 \pm 1.9$ & $13.8 \pm 2.2$ & $17.1 \pm 2.5$ & $7.3 \pm 1.2$ & $38.2 \pm 5.9$ & 0.40 \\
\hline$\approx 120$ & $\mathrm{a}, \mathrm{b}, \mathrm{c}, \mathrm{d}$ & 250 & $109.2 \pm 9.0$ & 0.45 & $13.5 \pm 2.1$ & $15.7 \pm 2.4$ & $20.6 \pm 2.8$ & $7.1 \pm 1.1$ & $43.4 \pm 6.3$ & 0.40 \\
\hline$\approx 150$ & $\mathrm{a}, \mathrm{b}, \mathrm{c}, \mathrm{d}$ & 280 & $120.5 \pm 12.8$ & 0.37 & $11.1 \pm 1.8$ & $13.1 \pm 2.0$ & $24.1 \pm 4.0$ & $14.1 \pm 2.1$ & $51.3 \pm 8.1$ & 0.43 \\
\hline
\end{tabular}

Despite the high concentration of glycerol in some runs (i.e., in the experiment with the highest $G l y_{0}$ concentration into the medium this quantity was $\approx 155 \mathrm{~g} / \mathrm{L}$ ), the microorganism presented an appreciable DCW production, providing evidence again of the suitability of this substrate for strains of this species $[8,11,16,29,44-48]$. Though, the $\mathrm{DCW}_{\max }$ quantity somehow decreased with the $G l y_{0}$ concentration increase in the medium, indicating the potential inhibition exerted due to the high Gly 0 quantity added into the medium (in accordance with reports for other Y. lipolytica strains; see i.e., Papanikolaou et al. $[8,18,21])$. In all cases, and despite the fact that the $\mathrm{pH}$ in the medium remained always in values $\geq 4.5 \pm 0.1$, carbon catabolism was mostly directed towards the synthesis of polyols, while indeed low quantities of organic acids (mostly citric acid) were found into the medium; $C A$ concentrations were $\leq 3.0 \mathrm{~g} / \mathrm{L}$ for all culture phases and all Gly $y_{0}$ concentrations rested. In most cases in the literature in which Y. lipolytica strains have grown under nitrogen limitation on glycerol-based media and medium $\mathrm{pH}$ remaining $>4.5$, this event normally favored the biosynthesis and secretion into the medium of citric acid. In contrast, relatively low quantities of polyols were simultaneously synthesized $[8,23,40,46,48,49]$. However, in agreement with the behavior of the strain LMBF Y-46 that mostly produced polyols instead of citrate, despite the maintenance of $\mathrm{pH}$ in values ranging between 4.5-6.1, in recent years, some reports have indicated similar physiological behaviors of other wild-type Y. lipolytica strains cultivated on slightly acidic conditions (medium pH between 4.5-6.5) with glycerol employed as the substrate, in which mostly polyols have been synthesized $[15,16,18,36,37]$. As indicated, the glycerol uptake rate noticeably decreased with Gly increment into the medium. Despite significant extension of the culture time (i.e., up to $280 \mathrm{~h}$ that corresponds to $\approx 11.5$ days) for the 
high $G l y_{0}$ concentration media, glycerol was not fully consumed (see Table 1). Nevertheless, by taking into consideration that in high Gly $y_{0}$ concentration media in which glycerol had not been completely assimilated (Table 1) glycerol uptake was always constant, it is strongly possible that further incubation would decrease the content of glycerol even more and increase the Pol biosynthesis in these cultures.

Y. lipolytica LMBF Y-46 growth on glycerol in shake flasks with various Glyo concentrations into the medium was performed under full aerobic conditions; DOT was measured mainly at the phase in which polyols were secreted into the medium, and irrespective of the Gly quantities added into the medium, DOT values ranged between $20 \%$ and $50 \% v / v$. On the other hand, the more the Gly quantity into the medium increased, the more Pol concentration increased (Table 1), in accordance with results indicated for other wild-type Y. lipolytica strains [18,21,22]. Furthermore, in the experiment with the somehow lower $G l y_{0}$ concentration added into the medium $\left(G l y_{0} \approx 70 \mathrm{~g} / \mathrm{L}\right)$, when the glycerol concentration from the medium was exhausted, polyols re-consumption and new yeast cell biomass occurred (Table 1). Re-consumption of extra-cellular and previously synthesized polyols in favor of the biosynthesis of new cell material (or potentially the production of other metabolites, like citric acid) has been observed in batch cultures performed by various wild-type Y. lipolytica strains [20-22,35,38]. Moreover, as stated, when higher Gly concentrations were employed, in absolute values (viz. g/L), enhanced production of polyols occurred. It can be hypothesized that in the trials with high $G y_{0}$ concentrations, either the increment of carbon excess or the increased osmotic pressure into the medium due to high $G l y_{0}$ quantities $[2,4,10,13]$ enhanced Pol production in Y. lipolytica LMBF Y-46. On the other hand, the total conversion yield of the sum of polyols $(\mathrm{Pol}, \mathrm{g} / \mathrm{L})$ produced per unit of glycerol consumed $\left(Y_{\text {Pol/Gly }}, \mathrm{g} / \mathrm{g}\right)$, originated from linear regression of all of the experiments points of Pol produced $f$ (glycerol consumed) for the batch-flask runs at $G l y_{0} \approx 100,120$ and $150 \mathrm{~g} / \mathrm{L}$, seemed to be constant and $\approx 0.43 \mathrm{~g} / \mathrm{g}$ (Figure 2).

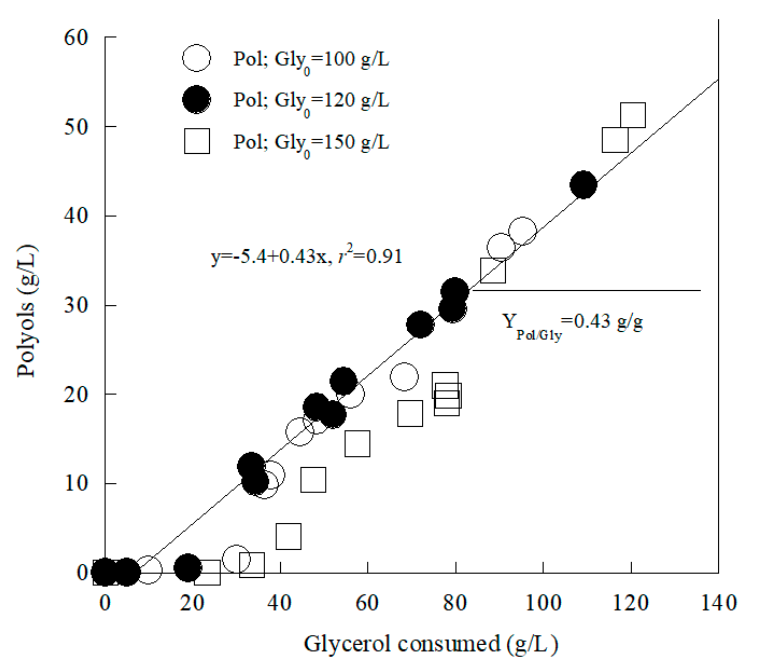

Figure 2. Total polyols $(\mathrm{Pol}, \mathrm{g} / \mathrm{L})$ produced vs. glycerol consumed $(\mathrm{g} / \mathrm{L})$ in shake-flask experiments during growth on pure glycerol by Yarrowia lipolytica LMBF Y-46, at elevated initial glycerol concentrations $\left(G l y_{0} \approx 100,120\right.$ and $\left.150 \mathrm{~g} / \mathrm{L}\right)$ under nitrogen-limited conditions. Culture conditions: growth on $250 \mathrm{~mL}$ conical flasks at $180 \pm 5 \mathrm{rpm}$, initial $\mathrm{pH}=6.0 \pm 0.1, \mathrm{pH}$ ranging between 4.5 and 6.1, incubation temperature $T=28 \pm 1{ }^{\circ} \mathrm{C}$. Each experimental point is the mean value of two independent determinations (SE $\leq 18 \%$ ).

In the above-mentioned figure, the results concerning the production of polyols in the trial in which $G l y_{0} \approx 70 \mathrm{~g} / \mathrm{L}$ were not incorporated, since in the latter case notably lower total polyols quantities, accompanied by remarkably depleted yield $Y_{P o l / G l y}$ values and higher yeast dry biomass quantities compared with the experiments where $G l y_{0} \approx 100,120$ and $150 \mathrm{~g} / \mathrm{L}$, were recorded (see Table 1). Moreover, as in the previously mentioned flask cultures ("effect of different glycerol sources under 
nitrogen limitation"), in this second set of experiments ( $G y_{0} \approx 70,100,120$ and $150 \mathrm{~g} / \mathrm{L}$ ) ammonium nitrogen was depleted from the medium at $t \approx 50-55 \mathrm{~h}$ after inoculation; in the second set of trials, the initial $\mathrm{NH}_{4}{ }^{+}$concentration was $\approx 550 \mathrm{mg} / \mathrm{L}$, while $\mathrm{NH}_{4}{ }^{+}$concentration at $t \approx 50-55 \mathrm{~h}$ after inoculation became $\approx 25 \pm 10 \mathrm{mg} / \mathrm{L}$, andtherefore, nitrogen limitation, accompanied by polyols secretion was noted. In the early stages of the cultivation ( $t \leq 50 \mathrm{~h}$ after inoculation), thus, no polyols biosynthesis was observed. Nevertheless, and despite the fact that at the early culture steps glycerol did not contribute to polyols production, the representation of $\operatorname{Pol}$ produced $f$ (glycerol consumed) and the linear regression performed for the batch-flask runs carried out makes sense, as most of the experimental points were found after nitrogen depletion where glycerol assimilation mostly contributed to the synthesis of polyols, whereas the correlation coefficient of the regression $\left(r^{2}=0.91\right)$ is quite satisfactory (Figure 2).

The metrics of polyols produced by yeasts cultivated on glycerol-based media and belonging to Yarrowia and Candida clades, and their comparisons with the current investigation, are presented in Table 2.

Table 2. Metrics of production of polyols by several yeasts belonging to Yarrowia and Candida clades during growth on glycerol in several fermentation modes. Comparison with the current study.

\begin{tabular}{|c|c|c|c|c|c|c|c|}
\hline Strain & $\begin{array}{c}\text { Ery } \\
(g / L)\end{array}$ & $\begin{array}{c}\text { Ml } \\
(\mathrm{g} / \mathrm{L})\end{array}$ & $\begin{array}{c}\text { Ara } \\
(\mathrm{g} / \mathrm{L})\end{array}$ & $\begin{array}{c}P o l \\
(\mathrm{~g} / \mathrm{L})\end{array}$ & $\begin{array}{c}Y_{P o l / G l y} \\
(\mathrm{~g} / \mathrm{g})\end{array}$ & Cultivation Type & Reference \\
\hline $1.22 \&$ & 93.5 & 34.0 & - & 127.5 & 0.43 & Fed-batch reactor & Rymowicz et al. [46] \\
\hline Wratislavia 1.31 * & 132.0 & 23.0 & - & 155.0 & 0.52 & Fed-batch reactor & Rymowicz et al. [46] \\
\hline Wratislavia K1 * & 170.0 & 12.0 & - & 182.0 & 0.60 & Fed-batch reactor & Rymowicz et al. [46] \\
\hline CCY-29-26-3 \& & 23.0 & 2.6 & 2.3 & 27.9 & 0.40 & Batch flasks & Tomaszewska et al. [29] \\
\hline CCY-29-26-4 \& & 26.7 & 1.0 & 2.2 & 29.9 & 0.40 & Batch flasks & Tomaszewska et al. [29] \\
\hline A- $15^{\&}$ & 71.0 & 8.0 & 1.8 & 80.8 & 0.50 & Batch reactor & Tomaszewska et al. [29] \\
\hline A UV'1 * & 63.0 & 8.8 & 9.2 & 81.0 & 0.50 & Batch reactor & Tomaszewska et al. [29]) \\
\hline Wratislavia K1 * & 80.0 & 2.6 & 0.3 & 82.9 & 0.51 & Batch reactor & Tomaszewska et al. [29] \\
\hline Wratislavia K1 * & 135.5 & 3.9 & 0.1 & 139.5 & 0.58 & Repeated-batch reactor & Mirończuk et al. [31] \\
\hline Wratislavia K1 * & 208.0 & 0.2 & - & 208.2 & 0.41 & Repeated-batch reactor & Mirończuk et al. [31] \\
\hline Wratislavia 1.31 * & 26.2 & 16.8 & 3.7 & 46.7 & 0.36 & Batch reactor & Tomaszewska et al. [48] \\
\hline Wratislavia AWG7 * & 25.7 & 17.1 & 2.7 & 45.5 & 0.30 & Batch reactor & Tomaszewska et al. [48] \\
\hline Wratislavia K1 * & 40.7 & 15.1 & 2.9 & 58.7 & 0.40 & Batch reactor & Tomaszewska et al. [48] \\
\hline $\mathrm{MK} 1{ }^{*}$ & 79.5 & 2.7 & 0.4 & 82.6 & 0.55 & Batch reactor & Mirończuk et al. [50] \\
\hline MK1 * & 138.8 & 3.3 & 0.3 & 142.4 & 0.69 & Repeated-batch reactor & Mirończuk et al. [50] \\
\hline MK1 * & 177.3 & 2.2 & - & 179.5 & 0.67 & Repeated-batch reactor & Mirończuk et al. [50] \\
\hline CBS10146 ${ }^{\text {点 }}$ & 44.6 & 5.2 & 10.5 & 60.3 & 0.53 & Batch reactor & Rakicka et al. [51] \\
\hline 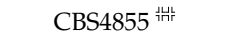 & 33.4 & 7.6 & 6.8 & 47.8 & 0.43 & Batch reactor & Rakicka et al. [51] \\
\hline CBS11013 缁皆 & 35.4 & 0.6 & 8.9 & 44.9 & 0.41 & Batch reactor & Rakicka et al. [51] \\
\hline FCY $214 *$ & 79.4 & n.i. & n.i. & 79.4 & 0.48 & Batch reactor & Carly et al. [35] \\
\hline FCY $218 *$ & 80.6 & n.i. & n.i. & 80.6 & 0.53 & Batch reactor & Carly et al. [35] \\
\hline HA $829 \& \$$ & $\approx 4$ & $\approx 28$ & $\approx 6$ & $\approx 38$ & n.i. & Batch reactor & Egermeier et al. [36] \\
\hline HA $1251 \& \$$ & $\approx 4$ & $\approx 32$ & $\approx 5$ & $\approx 41$ & n.i. & Batch reactor & Egermeier et al. [36] \\
\hline ACA YC $5029 \& \$$ & 33.6 & 28.9 & - & 62.5 & 0.45 & Batch flasks & Papanikolaou et al. [18] \\
\hline ACA YC $5030^{\&} \$$ & 35.5 & 32.1 & - & 67.6 & 0.49 & Batch flasks & Papanikolaou et al. [18] \\
\hline $\mathrm{AIB}^{\&}$ & 56.7 & 12.6 & 6.0 & 75.3 & 0.49 & Fed-batch reactor & Rakicka et al. [52] \\
\hline AIB pADUTGUT1 * & 82.2 & 11.0 & 7.5 & 100.7 & 0.67 & Fed-batch reactor & Rakicka et al. [52] \\
\hline ACA-DC $5029 \& \$$ & 65.8 & 6.5 & 3.4 & 75.7 & 0.44 & Batch flasks & Sarris et al. [53] \\
\hline ACA-DC $5029 \& \$$ & 15.6 & 10.5 & 3.4 & 29.5 & 0.39 & Batch flasks & Sarris et al. [49] \\
\hline M53-S * & 69.9 & 10.1 & - & 80.0 & 0.80 & Batch flasks & Liu et al. [54] \\
\hline M53-S * & 72.5 & 10.0 & - & 82.5 & 0.82 & Batch reactor & Liu et al. [54] \\
\hline LMBF Y-46 & 24.1 & 13.1 & 14.1 & 51.3 & 0.43 & Batch flasks & Present study \\
\hline
\end{tabular}

With the exception of a scarce number of reports [50,52,54], the yield $Y_{P o l / G l y}$ has rarely been $>0.60 \mathrm{~g} / \mathrm{g}$ and in most cases it ranged between 0.40 and $0.55 \mathrm{~g} / \mathrm{g}$, in accordance with the results of the current submission. The majority of the studies dealing with the production of polyols by Y. lipolytica strains, has been carried out with the use of mutant (i.e., acetate negative ones) or genetically engineered strains, that have been reported to produce, in many cases, relatively or even much higher Pol quantities compared to the present study (see Table 2). On the other hand, strain LMBF Y-46 is wild-type novel yeast isolate, originated from fish-origin products [17], that has not been previously studied in detail, 
especially concerning its physiological behavior. Moreover, for almost all of the reports indicated in Table 2, trials had been performed in $\mathrm{pH}$ values $\approx 3.0-3.5$, whereas in the current investigation the $\mathrm{pH}$ value was $\geq 4.5$, therefore, it is attainable to obtain higher Pol quantities with the use of the LMBF Y-46 strain after further culture optimization, specifically as regards growth in lower $\mathrm{pH}$ values.

\subsection{Metabolic Characterization of Yarrowia lipolytica LMBF Y-46: Scale-Up in Laboratory-Scale Bioreactor}

In the next step of this investigation, the bioprocess of glycerol fermentation by Y. lipolytica LMBF Y-46 was scaled-up in a bench-top laboratory-scale bioreactor (active process volume $=2.0 \mathrm{~L}$ ) which allowed fine $\mathrm{pH}$ control and dissolved oxygen measurement. Trials with $G l y_{0}$ concentration adjusted to $\approx 100 \mathrm{~g} / \mathrm{L}$ were performed $\left(\left(\mathrm{NH}_{4}\right)_{2} \mathrm{SO}_{4}\right.$ at $2.0 \mathrm{~g} / \mathrm{L}$ and yeast extract at $3.0 \mathrm{~g} / \mathrm{L}$ were set into the medium). The choice of $G l y_{0} \approx 100 \mathrm{~g} / \mathrm{L}$ was based on the results indicated in Table 1; precisely, in flask cultures with this Gly $y_{0}$ concentration, glycerol was almost completely consumed by the microorganism in a not excessively high incubation time (c. $180 \mathrm{~h}$ ), while equally, $\mathrm{DCW}_{\max }$ concentration was substantially high not being seriously influenced by the inhibition exerted due to high Gly $y_{0}$ concentrations into the medium (see Table 1). The obtained results in the equivalent trials between the shake-flask and the bioreactor culture are depicted in Table 3, while the evolution of DCW and glycerol in the two experiments is presented in Figure $3 \mathrm{a}, \mathrm{b}$. From the obtained results it can be indicated that drastically different kinetic and physiological profiles were recorded between the two experiments; in the bioreactor trial, much higher total biomass production occurred. This biomass value was obtained significantly more rapidly than the flask culture. On the other hand, the $\mu_{\max }$ value between the shake-flask and the bioreactor trial (for the calculation see Section 2.2) was not substantially different between the two experiments ( $\mu_{\max } \approx 0.16 \mathrm{~h}^{-1}$ for both performed cultures). In contrast, the biomass production rate $r_{X}\left(=\frac{\Delta X}{\Delta t}\right.$, in $\mathrm{g} / \mathrm{L} / \mathrm{h}$; calculation performed when $X$ obtained its maximum value), was drastically higher in the bioreactor experiment compared with the shake-flask one (viz. $0.506 \mathrm{vs}$. $0.08 \mathrm{~g} / \mathrm{L} / \mathrm{h}$ ). Moreover, glycerol consumption was drastically higher in the bioreactor trial compared with the flask culture (see Table 3 and Figure 3b). As previously, fitting of the experimental data through linear regression of the remaining glycerol concentration $f$ (fermentation time) demonstrated linear glycerol consumption rate $\mathrm{r}_{\mathrm{Gly}}$ (although, $r^{2}$ value was only 0.90 for the bioreactor experiment vs. 0.99 for the shake-flask trial; see Figure $3 \mathrm{~b}$ ) that was $0.52 \mathrm{~g} / \mathrm{L} / \mathrm{h}$ for the flask experiment and $>3$-fold time greater for the bioreactor culture (the $\mathrm{r}_{\mathrm{Gly}}$ value for the latter case was $=1.85 \mathrm{~g} / \mathrm{L} / \mathrm{h}$ ).

Table 3. Quantitative data of cultures of Yarrowia lipolytica LMBF Y-46 on glycerol-based media in which initial glycerol concentration $\left(G l y_{0}\right) \approx 100 \mathrm{~g} / \mathrm{L}$ was added (nitrogen was added as ammonium sulfate at $2.0 \mathrm{~g} / \mathrm{L}$ and yeast extract at $3.0 \mathrm{~g} / \mathrm{L}$ ) in shake-flask and batch bioreactor experiments. Culture conditions: for the flask experiment as in Table 1. For the bioreactor experiment: agitation $800 \pm 5 \mathrm{rpm}$, $\mathrm{pH}=6.0 \pm 0.1$, aeration fluctuating from 0.1 up to $2.0 \mathrm{vvm}$ in order to have a DOT $\geq 10 \% v / v$, incubation temperature $T=28 \pm 1{ }^{\circ} \mathrm{C}$, active volume $=2.0 \mathrm{~L}$. Culture details when the maximum concentration of polyols ( $P o l, g / L)(a)$, citric acid (CA, g/L) (b) and yeast dry cell biomass (X, g/L) (c) was achieved. $\mathrm{Ml}$, Ery and Ara is the concentration of mannitol, erythritol and arabitol, respectively (in $\mathrm{g} / \mathrm{L}$ ), at the given fermentation times. Each experimental point presented is the mean value of two independent determinations.

\begin{tabular}{|c|c|c|c|c|c|c|c|c|c|c|c|}
\hline $\begin{array}{l}\text { Gly } \\
(\mathrm{g} / \mathrm{L})\end{array}$ & & $\begin{array}{c}\text { Time } \\
\text { (h) }\end{array}$ & $\begin{array}{c}G l y_{\text {cons }} \\
(\mathrm{g} / \mathrm{L})\end{array}$ & $\begin{array}{c}X \\
(\mathrm{~g} / \mathrm{L})\end{array}$ & $\begin{array}{c}\text { Ml } \\
(\mathrm{g} / \mathrm{L})\end{array}$ & $\begin{array}{c}\text { Ery } \\
(\mathrm{g} / \mathrm{L})\end{array}$ & $\begin{array}{l}\text { Ara } \\
(\mathrm{g} / \mathrm{L})\end{array}$ & $\begin{array}{c}C A \\
(\mathrm{~g} / \mathrm{L})\end{array}$ & $\begin{array}{c}\mathrm{Pol} \\
(\mathrm{g} / \mathrm{L})\end{array}$ & $\begin{array}{c}Y_{C A / G l y} \\
(\mathrm{~g} / \mathrm{g})\end{array}$ & $\begin{array}{c}Y_{P o l / G l y} \\
(\mathrm{~g} / \mathrm{g})\end{array}$ \\
\hline$\approx 100$ Flasks & $a, c$ & 183 & $95.4 \pm 7.1$ & $15.0 \pm 1.9$ & $13.8 \pm 2.2$ & $17.1 \pm 2.5$ & $7.3 \pm 1.2$ & - & $38.2 \pm 5.9$ & - & 0.40 \\
\hline$\approx 100$ & $a, c$ & 41.5 & $86.8 \pm 6.1$ & $21.0 \pm 3.1$ & $3.0 \pm 0.5$ & - & - & $20.4 \pm 3.3$ & $3.0 \pm 0.5$ & 0.24 & 0.03 \\
\hline Bioreactor & $\mathrm{b}$ & 65 & $103.5 \pm 9.9$ & $19.0 \pm 3.4$ & $0.5 \pm 0.1$ & - & - & $42.4 \pm 5.5$ & $0.5 \pm 0.1$ & 0.41 & 0.004 \\
\hline
\end{tabular}




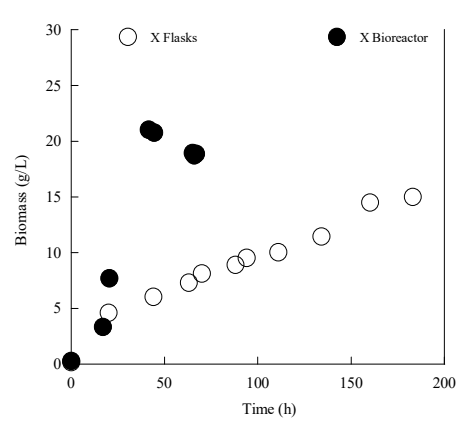

(a)

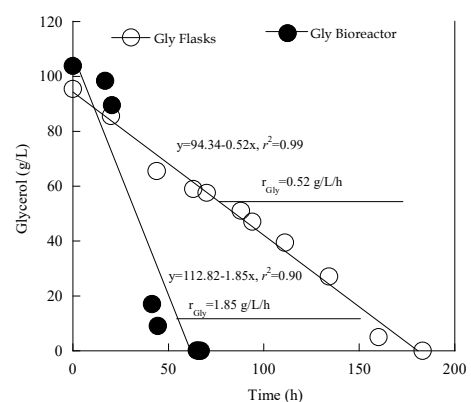

(b)

Figure 3. Kinetics of dry yeast cell mass production $(X, g / L)($ a) and glycerol assimilation $(G l y, g / L)$ (b) in shake flask and batch bioreactor experiment of Yarrowia lipolytica LMBF Y-46 during growth on pure glycerol, at initial glycerol concentration $\left(G l y_{0}\right) \approx 100 \mathrm{~g} / \mathrm{L}$ under nitrogen-limited conditions. Culture conditions as in Tables 1 and 3. Each experimental point is the mean value of two independent determinations ( $\mathrm{SE} \leq 18 \%)$.

The most profound difference between the flask and the bioreactor trial was observed in the spectrum of the final fermentation products between the two cultures; in the shake-flask trial (and despite the fact that $\mathrm{pH}$ was $>4.5$-as previously stated in most of the shake-flask experiments $\mathrm{pH}$ value was found within the range 4.8-5.8) the major metabolites synthesized were the three previously indicated polyols $\left(\mathrm{Pol}=38.2 \mathrm{~g} / \mathrm{L}, Y_{P o l} / \mathrm{Gly}=0.40 \mathrm{~g} / \mathrm{g}\right)$. In contrast, a remarkable metabolic shift in which mostly citric acid was produced occurred in the bioreactor experiment. Specifically, a $C A_{\max }$ quantity $=42.4 \mathrm{~g} / \mathrm{L}$ (simultaneous $Y_{C A / G l y}=0.41 \mathrm{~g} / \mathrm{g}$ ) was reported, whereas insignificant quantities of mannitol and negligible ones or arabitol and erythritol were reported in the batch bioreactor experiment (Table 3). Iso-citric acid quantity ranged between $5-9 \%$ of the total citric acid concentration determined. In the above-mentioned fermentation point, iso-citric acid corresponded to $8.0 \% w / w$ of $C A$ formed. Moreover, it is interesting to indicate that the maximum volumetric productivity of $C A\left(P_{C A \max }\right)$ achieved in the current batch culture $\left(P_{C A \max }\right.$ calculated as $P_{C A \max }=\frac{C A_{\max }}{\Delta t}$, where $\Delta t$ is the fermentation time in the batch or fed-batch culture requested to achieve this $C A_{\max }$ value) was $\approx 0.65 \mathrm{~g} / \mathrm{L} / \mathrm{h}$, being certainly comparable with the highest values reported by other wild-type or mutant $Y$. lipolytica strains cultivated in batch (0.52-0.85 g/L/h [55]), fed-batch (i.e., $0.40-0.93 \mathrm{~g} / \mathrm{L} / \mathrm{h}$ [56-59]), and continuous (between 0.70 and $1.30 \mathrm{~g} / \mathrm{L} / \mathrm{h}$ [60]) bioreactor operations (in the cited batch and fed-batch cultures, $P_{C A \max }$ was calculated as in the present study, whereas in the continuous cultures, $P_{C A}$ was calculated as $P_{C A}=C A \cdot D$, where $C A$ was the concentration at the steady-state and $D$ was the dilution rate imposed). It is noted that in the shake-flask citric acid production experiments, the achieved productivities (calculated as previously stated) are, in general, much lower $(0.07-0.25 \mathrm{~g} / \mathrm{L} / \mathrm{h})[8,19,23,40,49,53,61,62]$.

The completely different metabolic profile observed between the shake-flask and the batch bioreactor trial should be attributed to the different agitation/aeration regime between the two cultures and more specifically to the higher level of oxygenation that occurred in the bioreactor experiment; for all of the fermentation steps in which noticeable biosynthesis of polyols occurred in the shake-flask trials, DOT values in the flasks always ranged between $20 \%$ and $50 \% v / v$. On the contrary, in the bioreactor experiment, with the exception of the very early fermentation step $(t=20 \mathrm{~h})$ in which DOT $\approx 20.0 \% v / v$, rapidly afterwards, DOT level was always $>40 \%$, and at the end of the trial, when glycerol had been consumed and the maximum CA concentration was recorded $(=42.4 \mathrm{~g} / \mathrm{L})$, the DOT value was $>90 \% v / v$ (kinetics of DOT evolution not presented). On the other hand, this differentiation in the metabolic responses between flask and bioreactor cultures did not seem to be seriously attributed to the different $\mathrm{pH}$ values observed between these two types of cultures; $\mathrm{pH}$ is certainly a crucial culture parameter that may influence the final spectrum of products for $Y$. lipolytica cultures. It has been demonstrated that the very same strain cultivated under nitrogen limitation, can produce almost exclusively citric acid at medium $\mathrm{pH}$ values $=5.0-6.0$, while metabolic shift and almost exclusive production of polyols may 
occur when cultures are performed at $\mathrm{pH}$ values $=3.0-3.5[23,46,48,63]$. In the current investigation, the differences in the $\mathrm{pH}$ values between the flask ( $\mathrm{pH}$ mostly found within 4.8-5.8) and the reactor $(\mathrm{pH}=6.0 \pm 0.1)$ experiments were not so high, thus we assume that $\mathrm{pH}$ was not the principal factor affecting the differences in the metabolism observed between the flask and the reactor trials.

In a very similar physiological pattern with the strain LMBF Y-46, the wild-type food-derived strain ACA YC 5029, when cultivated in shake-flask trials (equally in $\mathrm{pH}>4.5$ ) produced mainly polyols (erythritol and mannitol). Minimal quantities of citric acid were synthesized [18]. In contrast, in well-agitated and aerated bioreactors $(800 \mathrm{rpm}$, aeration between 0.1 and $2.0 \mathrm{vvm}$ in order to always have a cascade of DOT $\geq 10 \%, v / v$ —significantly higher DOT values than $10 \% v / v$ were finally recorded) mainly citric acid was synthesized, whereas simultaneously insignificant biosynthesis of polyols occurred [18]. In agreement with these results and according to the literature, $C A$ biosynthesis is strongly influenced by the DOT values in the culture medium; Ferreira et al. [64], performing culture optimization of the strains Y. lipolytica W29 and CBS 2073, observed a clear positive effect of the oxygen mass transfer rate (OTR) upon the biosynthesis of $C A$ for these yeast strains during glycerol fermentation in shake-flask experiments. Likewise, in batch bioreactor experiments with the strain W29 growing on glycerol, $C A$ production was clearly favored in trials presenting higher oxygen volumetric mass transfer coefficients $\left(k_{\mathrm{La}}\right)$; therefore, increase in the initial $k_{\mathrm{La}}$ value from $7 \mathrm{~h}^{-1}$ to $55 \mathrm{~h}^{-1}$ led to a 7.8 -fold increase in the final concentration of citric acid in this strain [65]. In accordance with the mentioned results, for the acetate negative Y. lipolytica mutants Wratislavia 1.31 and Wratislavia AWG7 cultivated in batch glycerol-based bioreactor experiments, remarkable agitation into the medium ( $800 \mathrm{rpm}$ ) and cascade aeration ensuring DOT $>40 \% v / v$ throughout the culture clearly favored $C A$ in these strains; for instance, under this aeration regime the strain Wratislavia 1.31 achieved a $C A_{\max }=92.8 \mathrm{~g} / \mathrm{L}$, with yield $Y_{C A / G l y} \approx 0.63 \mathrm{~g} / \mathrm{g}$ [66]. Concluding, it may be indicated that a variety of external factors like medium $\mathrm{pH}$, salt addition and aeration may critically influence the physiological and kinetic behavior of $Y$. lipolytica yeast $[10-12,14,15]$. However, such high discrepancies in the final spectrum of metabolites between shake-flask and aerated/agitated batch-bioreactor experiment that have been observed in the current investigation, is indeed, of notable importance.

Given that Y. lipolytica LMBF Y-46 was revealed as capable at rapidly assimilating glycerol and efficiently converting it into citric acid in bioreactor experiments, a pulsed fed-batch bioreactor trial (like the one performed by Förster et al. [57] and Tan et al. [67]), in which culture conditions (viz. aeration, agitation, $\mathrm{pH}$ ) were the same as in the previous batch, was performed (see Figure $4 \mathrm{a}-\mathrm{c}$ ). Significant glycerol uptake occurred, whereas noticeable DCW quantities were synthesized relatively early $\left(X_{\max } \approx 21 \mathrm{~g} / \mathrm{L}\right.$ ) with these values being drastically depleted afterwards due to significant cell autolysis (final DCW quantity when the culture stopped $\approx 11 \mathrm{~g} / \mathrm{L}$; Figure $4 \mathrm{a}$ ). Despite significant cell autolysis, yeast biomass maintained its viability, since simultaneously with biomass decrease noticeable glycerol uptake occurred and remarkable quantities of $C A$ were synthesized. When the culture stopped, a noticeable $C A$ quantity $(=101.1 \mathrm{~g} / \mathrm{L}$ ) with a simultaneous quite high $C A$ volumetric productivity $(\approx 0.61 \mathrm{~g} / \mathrm{L} / \mathrm{h})$ were recorded (Figure $4 \mathrm{~b})$, with a global conversion of citric acid produced per unit of glycerol consumed $\left(Y_{C A / G l y}\right)$ being $=0.46 \mathrm{~g} / \mathrm{g}$ (Figure $4 \mathrm{c}$ ). In the above-mentioned fermentation point, iso-citric acid corresponded to $7.8 \% \mathrm{w} / \mathrm{w}$ of $C A$ formed $(=7.9 \mathrm{~g} / \mathrm{L})$. Although at the early steps of the bioreactor culture $(t=0-30 \mathrm{~h}$ after inoculation), the assimilation of glycerol did not contribute importantly to $C A$ formation (see Figure $4 \mathrm{~b}$ ), finally the representation of $C A$ produced $f$ (glycerol consumed) and the linear regression performed for the whole fed-batch culture carried presents interest, as for most of the experimental points glycerol assimilation mostly contributed to the synthesis of $C A$, whereas the correlation coefficient of the regression $\left(r^{2}=0.97\right)$ presented a very satisfactory value (Figure 4c). Moreover, $C A$ production was connected with a high DOT in the medium (Figure 4a), whereas interestingly and in accordance with a number of reports indicated in the literature [40,68], CA production linearly increased with the time $\left(r^{2}=0.97\right)$, resulting in a global $\mathrm{r}_{\mathrm{CA}}=0.58 \mathrm{~g} / \mathrm{L} / \mathrm{h}$ (Figure $4 \mathrm{~b}$ ). Metrics of citric acid production by wild-type, mutant and genetically modified Y. lipolytica strains cultivated in bioreactor experiments with several types of carbon sources 
employed as substrates, in various fermentation configurations and their comparisons with the current investigation, are depicted in Table 4.

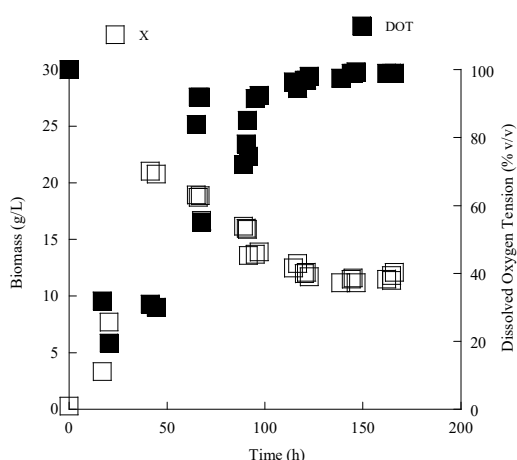

(a)

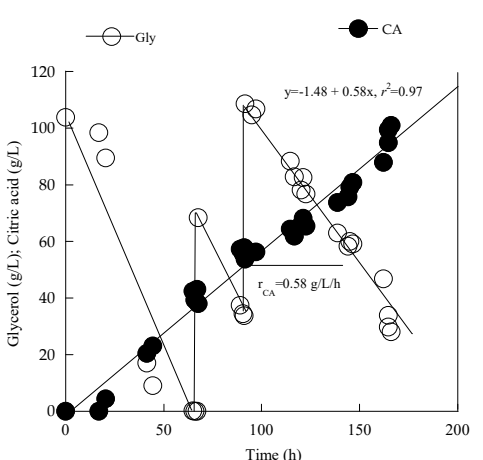

(b)

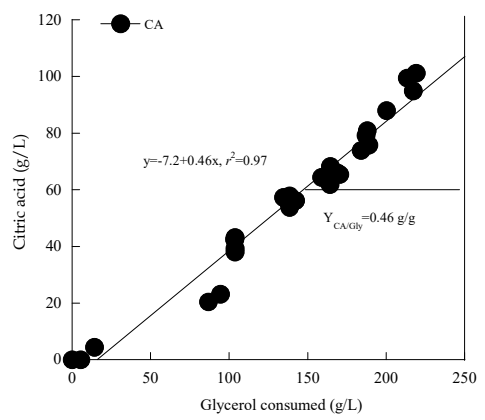

(c)

Figure 4. Kinetics of dry yeast cell mass evolution $(X, \mathrm{~g} / \mathrm{L})$ and dissolved oxygen tension $(\%, v / v)$ vs. time (a), glycerol evolution ( $G l y, g / L)$ and citric acid production $(C A, g / L)$ vs. time $(\mathbf{b})$, and citric acid produced $(C A, g / L)$ vs. glycerol consumed $(\mathrm{g} / \mathrm{L})(\mathrm{c})$ by Yarrowia lipolytica LMBF Y-46, during growth on pure glycerol in pulsed fed-batch bioreactor experiments under nitrogen-limited conditions. Culture conditions as in Table 3. Each experimental point is the mean value of two independent determinations $(\mathrm{SE} \leq 18 \%)$.

The maximum CA quantity obtained in the current investigation (=101.2 g/L) compares favorably with most cultures of wild-type Y. lipolytica strains, while this value is also higher compared with that obtained for various mutants of genetically engineered strains (see Table 4). Concerning the conversion yield $Y_{C A / G l y}$ values achieved in the batch and fed-batch bioreactor operations of the present study $(=0.41-0.46 \mathrm{~g} / \mathrm{g})$, they are slightly lower compared with the relevant studies in which other Y. lipolytica strains were grown on glycerol $[60,63,66,67]$. The growth of $Y$. lipolytica strains on other substrates that present higher carbon percentage and reductance degree compared with glycerol (i.e., oils or ethanol), naturally is accompanied by higher conversion yields [56,71,77] compared with the present study. On the other hand, there are a number of reports in which mutants of genetically modified strains have attained greater $C A_{\max }$ quantities compared with the current submission (i.e., $C A$ quantities ranging between 102-140 g/L; [56,57,67,72,77]), whereas in a scarce number of investigations, indeed tremendous $C A_{\max }$ quantities (i.e., 161 and $175 \mathrm{~g} / \mathrm{L}$ ) have been reported [73,74]. On the other hand, in all the above-mentioned cases, mutant or genetically engineered strains have been implicated in these bioprocesses, whereas the strain LMBF Y-46, as previously indicated, is a food-originated wild-type new isolate that has not previously been systematically studied. Moreover, optimization of the $C A$ production bioprocess via the above-strain as regards medium $\mathrm{pH}$, agitation, oxygen uptake rate etc., can further increase the achieved $C A$ production. Likewise, further incubation in the already realized fed-batch experiment, could further enhance the $C A_{\max }$ quantity achieved by the strain LMBF Y-46 (see Figure 4b). 
Table 4. Metrics of production of citric acid by yeasts belonging to the species Yarrowia (Candida-Saccharomycopsis-Endomycopsis) lipolytica, during growth on various substrates in bioreactor experiments. Comparisons with the current study.

\begin{tabular}{|c|c|c|c|c|c|}
\hline Strain & $\begin{array}{c}\text { Citric Acid } \\
\text { (g/L) }\end{array}$ & Substrate & $\begin{array}{l}\text { Yield } \\
\text { (g/g) }\end{array}$ & $\begin{array}{c}\text { Bioreactor } \\
\text { Configuration }\end{array}$ & Reference \\
\hline NRRL Y-7576 $\$$ & 51.5 & Glucose & 0.71 & Fed-batch & Klasson et al. [69] \\
\hline $\mathrm{Y}-1095^{\$}$ & 78.5 & Glucose & 0.79 & Fed-batch & Rane and Sims [70] \\
\hline ATCC 20346 & 69.0 & Glucose & 0.52 & Fed-batch & Moresi [68] \\
\hline $\mathrm{N} 1 *$ & 120.0 & Ethanol & 0.85 & Fed-batch & Kamzolova et al. [71] \\
\hline $187 / 1^{\$}$ & 135.1 & Rapeseed oil & 1.55 & Fed-batch & Kamzolova et al. [56] \\
\hline Wratislavia AWG7* & 88.1 & Crude glycerol & 0.46 & Batch & Rymowicz et al. [44] \\
\hline Wratislavia K1 * & 75.7 & Crude glycerol & 0.40 & Batch & Rymowicz et al. [44] \\
\hline H222-S4(p67ICL1)T5* & $91.0^{\&}$ & Sucrose & 0.53 & Fed-batch & Förster et al. [57] \\
\hline H222-S4(p67ICL1)T5* & $133.0 \&$ & Sucrose & 0.78 & Fed-batch & Förster et al. [57] \\
\hline A-101-1.22 * & $119.1^{\&}$ & Crude glycerol & 0.64 & Fed-batch & Rymowicz et al. [47] \\
\hline A-101-1.22 * & $115.6^{\&}$ & Crude glycerol & 0.68 & Repeated batch & Rymowicz et al. [47] \\
\hline A- $101^{\$}$ & 69.3 & Glucose & 0.45 & Batch & Rywińska et al. [55] \\
\hline A-101 $\$$ & 66.5 & Pure glycerol & 0.44 & Batch & Rywińska et al. [55] \\
\hline A-101 \$ & 66.8 & Crude glycerol & 0.43 & Batch & Rywińska et al. [55] \\
\hline Wratislavia 1.31 * & 76.4 & Glucose & 0.52 & Batch & Rywińska et al. [55] \\
\hline Wratislavia 1.31 * & 63.9 & Pure glycerol & 0.40 & Batch & Rywińska et al. [55] \\
\hline Wratislavia 1.31 * & 82.0 & Crude glycerol & 0.53 & Batch & Rywińska et al. [55] \\
\hline Wratislavia 1.31 * & $126.0^{\&}$ & Crude glycerol & 0.63 & Fed-batch & Rywińska et al. [72] \\
\hline Wratislavia AWG7* & $157.5^{\&}$ & Crude glycerol & 0.58 & Fed-batch & Rywińska et al. [72] \\
\hline Wratislavia AWG7* & $160.5^{\&}$ & Crude glycerol & 0.81 & Repeated batch & Rywińska and Rymowicz [73] \\
\hline Wratislavia 1.31 * & $124.9^{\&}$ & Crude glycerol & 0.59 & Repeated batch & Rywińska and Rymowicz [73] \\
\hline $\mathrm{N} 15^{\$}$ & 98.0 & Pure glycerol & 0.70 & Fed-batch & Kamzolova et al. [61] \\
\hline NG40/UV7 * & 175.0 & Rapeseed oil & 1.50 & Fed-batch & Kamzolova et al. [74] \\
\hline Wratislavia AWG7* & 63.3 & Pure glycerol & 0.67 & Continuous & Rywińska et al. [60] \\
\hline Wratislavia 1.31 * & 92.8 & Pure glycerol & 0.63 & Batch & Rywińska et al. [66] \\
\hline SWJ-1b * & 84.0 & Inulin & 0.89 & Batch & Liu et al. [75] \\
\hline NG40/UV7 * & 115.0 & Pure glycerol & 0.64 & Fed-batch & Morgunov et al. [59] \\
\hline NG40/UV7 * & 112.0 & Crude glycerol & 0.90 & Fed-batch & Morgunov et al. [59] \\
\hline Wratislavia AWG7 * & 85.7 & Crude glycerol & 0.52 & Batch & Tomaszewska et al. [48] \\
\hline Wratislavia $\mathrm{K} 1$ * & 65.0 & Crude glycerol & 0.43 & Batch & Tomaszewska et al. [48] \\
\hline SWJ-1b * & 101.6 & Glucose & 0.89 & Fed-batch & Tan et al. [67] \\
\hline CBS $6114^{\$}$ & $\approx 55^{\&}$ & Pure glycerol & n.i. & Batch & Egermeier et al. [36] \\
\hline $\mathrm{H} 222^{\$}$ & $\approx 50 \&$ & Pure glycerol & n.i. & Batch & Egermeier et al. [36] \\
\hline DSM $1345^{\$}$ & $\approx 52 \&$ & Pure glycerol & n.i. & Batch & Egermeier et al. [36] \\
\hline VKM Y-2373 ${ }^{\$}$ & $80-85$ & Glucose & $0.70-0.75$ & Batch & Kamzolova and Morgunov [76] \\
\hline ACA YC $5029^{\$}$ & 39.0 & Crude glycerol & 0.42 & Batch & Papanikolaou et al. [18] \\
\hline NG40/UV5 * & 140.0 & Rapeseed oil & 1.50 & Fed-batch & Morgunov et al. [77] \\
\hline NG40/UV5 * & 108.8 & Glucose & 0.80 & Fed-batch & Morgunov et al. [77] \\
\hline NG40/UV5 * & 87.0 & Crude glycerol & 0.64 & Fed-batch & Morgunov et al. [77] \\
\hline $\mathrm{K} 57^{\$}$ & 72.1 & Glucose & 0.77 & Batch & Carsanba et al. [62] \\
\hline AJD pADUTGut $1 / 2$ * & $75.9 \& \&$ & Crude glycerol & 0.51 & Batch & Rzechonek et al. [63] \\
\hline LMBF Y-46 ${ }^{\$}$ & $42.4^{\&}$ & Pure glycerol & 0.41 & Batch & Present study \\
\hline LMBF Y-46 ${ }^{\$}$ & $101.3^{\&}$ & Pure glycerol & 0.46 & Fed-batch & Present study \\
\hline
\end{tabular}

\subsection{Modeling the Production of Polyols by Yarrowia lipolytica LMBF Y-46 Growing on Glycerol in Shake-Flask Experiments}

The production of polyols by Y. lipolytica LMBF Y-46 in shake-flask experiments in which increasing $G l y_{0}$ concentrations were adjusted into the medium while the initial nitrogen concentration remained constant (see kinetic results in Table 1) was numerically modeled. Modeling Y. lipolytica growth on glycerol and the accompanied total polyols production, was based on the equations and the numerical procedure used in describing the lipid production by Cryptococcus curvatus, grown on commercial-type xylose [78], originated from the modeling of citric acid production by another Y. lipolytica strain growing batch-wise in glucose-enriched olive mill wastewater-based media [79]. The governing equations and the associated kinetic parameters related to yeast DCW production, glycerol consumption and polyols accumulation into the medium for the experiments with the three higher glycerol concentrations employed, that is, for 100, 120 and $150 \mathrm{~g} / \mathrm{L}$ nominal concentrations, are presented on Table 5. In the 
present work, a Verhulst-type equation [79] in which the glycerol decreasing ratio, Gly/Gly $y_{0}$, according to the approach proposed by Aggelis and colleagues [80-82], was used in order to quantitatively describe the specific growth rate $(\mu)$. Note that the treatment of biomass concentration at the beginning of the experiments (i.e., $X$ at $t=0$ ) as an adjustable parameter (Table 5) highly improved the quality of the fitting. Comparisons between experimental data and theoretical concentration values are depicted in Figure $5 \mathrm{a}-\mathrm{c}$, demonstrating a very satisfactory fitting for all runs performed.

Table 5. Governing equations and associated kinetic parameters related to biomass growth, glycerol consumption and polyols production during Yarrowia lipolytica culture on different glycerol concentrations.

\begin{tabular}{|c|c|c|c|c|c|}
\hline \multirow{3}{*}{ Equation } & \multirow{2}{*}{\multicolumn{2}{|c|}{ Number of Data Points }} & \multicolumn{3}{|c|}{ Glycerol Concentration $(\mathrm{g} / \mathrm{L})$} \\
\hline & & & 100 & 120 & 150 \\
\hline & & & & & \\
\hline \multirow{2}{*}{$\frac{d X}{d t}=\mu X$} & \multirow[b]{2}{*}{1} & $\mu_{\max }\left(\mathrm{h}^{-1}\right)$ & 0.0296 & 0.0252 & 0.0350 \\
\hline & & $X_{\max }\left(g_{X} / \mathrm{L}\right)$ & 20.63 & 16.94 & 10.62 \\
\hline \multirow{3}{*}{$\mu=\mu_{\max }\left(1-\frac{X}{X_{\max }}\right)\left(\frac{G l y}{G l y_{0}}\right)$} & \multirow{3}{*}{2} & $X$ at $t=0\left(\mathrm{~g}_{X} / \mathrm{L}\right)$ & 2.26 & 2.22 & 2.23 \\
\hline & & SSE & 13.09 & 9.48 & 8.03 \\
\hline & & $\mathrm{R}^{2}$ & 0.942 & 0.937 & 0.935 \\
\hline \multirow{2}{*}{$\frac{d P o l}{d t}=q_{P o l} X$} & \multirow{2}{*}{3} & $q_{\text {Polmax }}\left(\mathrm{g}_{\text {Pol }} /\left(\mathrm{g}_{X} \mathrm{~h}\right)\right)$ & 0.0415 & 0.0420 & 0.0251 \\
\hline & & $P_{0} l_{\max }\left(\mathrm{g}_{P o l} / \mathrm{L}\right)$ & 40.14 & 48.86 & 162.87 \\
\hline \multirow{2}{*}{$q_{P o l}=q_{P o l_{\max }}\left(1-\frac{P o l}{P o l_{\max }}\right)$} & \multirow{2}{*}{4} & SSE & 127.02 & 59.43 & 68.33 \\
\hline & & $\mathrm{R}^{2}$ & 0.951 & 0.974 & 0.981 \\
\hline \multirow{4}{*}{$-\frac{d G l y}{d t}=\mu \frac{1}{Y_{X / G l y}} X+q_{P o l} \frac{1}{Y_{P o l} / G l y} X$} & \multirow{4}{*}{5} & $Y_{X / G l y}\left(g_{X} / g_{G l y c}\right)$ & 0.2160 & 0.2749 & 0.1210 \\
\hline & & $Y_{P o l / G l y}\left(\mathrm{~g}_{P o l} / \mathrm{g}_{\text {Glyc }}\right)$ & 0.9997 & 0.6575 & 1.0586 \\
\hline & & SSE & 445.2 & 187.1 & 1027.8 \\
\hline & & $\mathrm{R}^{2}$ & 0.954 & 0.984 & 0.956 \\
\hline
\end{tabular}

SSE: Sum of squared errors.

The kinetic parameter values are comparable to the theoretical and experimental values recorded in the literature; specifically, the optimized parameter value for $\mu_{\max }$ in the current investigation $\left(\approx 0.03 \mathrm{~h}^{-1}\right)$, presented slightly lower values than that reported for other optimized $\mu_{\max }$ values for various Y. lipolytica strains cultivated batch-wise and producing a plethora of secondary metabolites (optimized $\mu_{\max }$ values ranged between 0.16 and $0.44 \mathrm{~h}^{-1}$ ) $[68,69,79,82]$. Optimized $q_{\text {Polmax }}$ values are found in the same order of magnitude with experimental values reported for other Y. lipolytica strains cultured on glycerol in batch experiments (0.002-0.04 $\mathrm{g}_{P o l} / \mathrm{g}_{X} / \mathrm{h}$; see: Tomaszewska et al. [29]; [48]). The same can be stressed concerning the optimized $Y_{X / G l y}$ values reported in the current investigation (Table 5), which presented remarkable similarities with optimized values achieved from application of several types of numerical modes for other $Y$. lipolytica strains cultured on glycerol $(=0.29-0.30 \mathrm{~g} / \mathrm{g})$ [82]. Equally, the above-mentioned optimized $Y_{X / G l y}$ values (see Table 5) present important similarities with experimentally achieved $Y_{X / G l y}$ values for various $Y$. lipolytica strains cultured on crude glycerol in batch experiments $(0.11-0.30 \mathrm{~g} / \mathrm{g})[18,22,29,48]$.

Optimized $Y_{\text {Pol/Gly }}$ values (ranging between 0.66 and $1.06 \mathrm{~g}_{P o l} / \mathrm{g}_{G l y}$ - see Table 5) were somehow overestimated when compared to the experimental data (see Table 1 and Figure 2). The biochemical patterns of polyols formation from glycerol fermentation, have not yet been completely elucidated [10,13], therefore, it is not known which the maximum theoretical conversion yield of glycerol into mannitol/erythritol and arabitol is. On the other hand, as previously stressed, with the exception of a scarce number of reports [50,52,54], experimental values of the $Y_{\text {Pol/Gly }}$ yield have rarely been reported to be $>0.60 \mathrm{~g} / \mathrm{g}$, therefore, the optimized $Y_{P o l / G l y}$ parameter values seem to be overestimated. Finally, the rather high $P o l_{\max }$ value of $162.87 \mathrm{~g} / \mathrm{L}$ obtained for the data of $G l y_{0} \approx 150 \mathrm{~g} / \mathrm{L}$, is attributed to the fact that glycerol was not totally consumed and polyols formation was still rising for the duration of the experiment (Figure 5) making predictions of Pol $_{\max }$ ambiguous. 

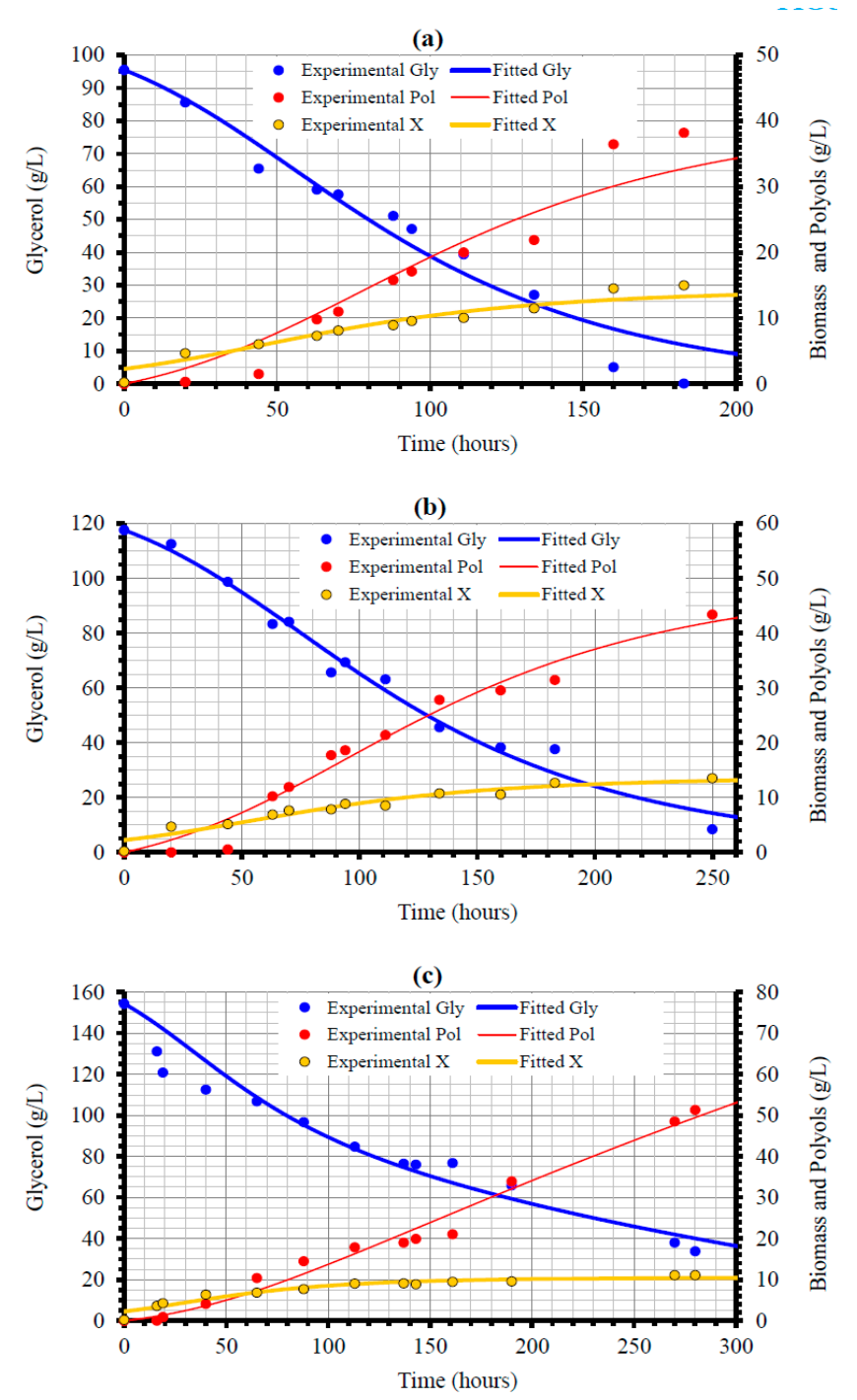

Figure 5. Experimental data and fitted values showing the evolution of biomass $(X)$, glycerol (Gly) and total polyols ( $\mathrm{Pol}$ ) concentration during growth of Yarrowia lipolytica on glycerol at: $\approx 100 \mathrm{~g} / \mathrm{L}(\mathbf{a}) ; \approx 120 \mathrm{~g} / \mathrm{L}$ (b); $\approx 150 \mathrm{~g} / \mathrm{L}$ (c), initial substrate concentrations in shake-flask experiments under nitrogen-limited conditions. Culture conditions as in Table 3. Each experimental point is the mean value of two independent determinations ( $\mathrm{SE} \leq 18 \%$ ).

The proposed model was not proved to be adequate to describe the data for the experiment with the $70 \mathrm{~g} / \mathrm{L}$ initial glycerol concentrations. A close look at the experimental data (Figure 6) reveals a continuous increase in biomass, above $20 \mathrm{~g} / \mathrm{L}$ values, even after glycerol depletion, at the expense of polyols. Such a behavior requires a different, rather unique modeling approach that was beyond the scope of the present work.

\subsection{Cellular Lipids of Yarrowia lipolytica LMBF Y-46}

Total cellular lipids were extracted and quantified for both the shake-flask and the bioreactor experiments, and the kinetics of the evolution of lipids in DCW are depicted in Figure 7a,b. In all cases, and as it had previously been demonstrated (Figure 1b), the microorganism under investigation did not produce remarkable quantities of total lipids in yeast biomass, irrespective of the culture configuration (flask or bioreactor experiments). In fact, as it has been demonstrated in several previous studies dealing with wild-type and genetically engineered $Y$. lipolytica strains cultured in batch experiments in both shake-flask and bioreactor trials, the oleaginous character of this species is strain dependent; 
in fact, in culture conditions of nitrogen starvation, in which carbon is found in the form of glucose, glycerol or similarly metabolized compounds (that favors the so-called "de novo" cellular lipid accumulation process; [5,83]), excess carbon is directed either towards the synthesis and secretion of low-molecular weight compounds (i.e., citric acid, polyols) or it is channeled towards the accumulation of storage lipids $[5,9,83]$. In Y. lipolytica, the above-indicated regulation is difficult, and it has been demonstrated that it depends on the availability of extra-cellular nitrogen (for example, Ochoa-Estopier and Guillouet [84] have demonstrated that a $\mathrm{C} / \mathrm{N}$ ratio of 11.7 yields lipid accumulation, while a ratio of 47.6 favors $C A$ production using D-stat continuous cultivation techniques), the utilization of doubleor multiple-limited media (for example in multiple-limited media and during growth on glucose or glycerol batch-wise, significant lipid quantities have been produced by $Y$. lipolytica yeasts that in simple nitrogen-limited ones produced mostly $C A[8,23,85])$, etc. Adaptive laboratory evolution strategies or genetic engineering approaches have resulted in the formation of $Y$. lipolytica strains that are capable of producing high amounts of cellular lipids and limited amounts of citric acid [43,86-88].

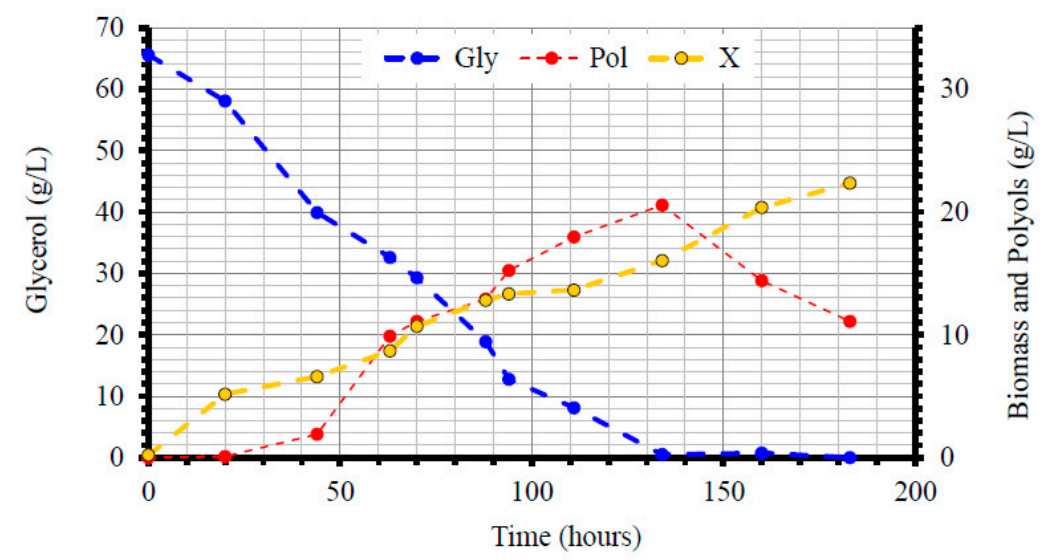

Figure 6. Kinetics of dry yeast cell mass production $(X, \mathrm{~g} / \mathrm{L})$, glycerol assimilation $(G l y, \mathrm{~g} / \mathrm{L})$ and total polyols production $(\mathrm{Pol}, \mathrm{g} / \mathrm{L})$ during Yarrowia lipolytica growth on initial glycerol adjusted to $\approx 70 \mathrm{~g} / \mathrm{L}$ in shake-flask experiments under nitrogen-limited conditions. Culture conditions as in Table 3. Each experimental point is the mean value of two independent determinations ( $\mathrm{SE} \leq 18 \%$ ).

In a number of cases, Y. lipolytica strains cultured in nitrogen-limited glucose- or glycerol-based media, produced sequentially lipid and extra-cellular low molecular-weight metabolites (citric acid and polyols); in the first steps of the culture, lipid accumulation was somehow induced, and then lipid in DCW values were depleted with time, even though significant substrate quantities remained unconsumed into the medium. At that period, secretion of citric acid or polyols, in high quantities, was carried out $[18,22,38-40,85]$. Exactly the same feature as regards lipid production and secretion of polyols was observed for the strain LMBF Y-46 in shake-flask experiments; somehow elevated lipid DCW values (i.e., 13-15\% w/w) were recorded at the earlier growth phases of the strain cultured on glycerol in flasks, irrespective of the Gly concentration set into the medium, and these values were significantly reduced when the culture proceeded (Figure 7a). The onset of secretion of polyols into the medium was carried out at c. $t=50 \pm 3 \mathrm{~h}$, occurring simultaneously with lipid DCW value depletion. In contrast, different kinetic profiles were recorded for the bioreactor experiment (Figure $7 \mathrm{~b}$ ). Compared with the equivalent flask experiment $\left(G l y_{0} \approx 100 \mathrm{~g} / \mathrm{L}\right)$, and despite the higher oxygenation that occurred in the fermentation vessel, the microorganism produced noticeably lower lipid quantities in the bioreactor experiment (see Figure $7 \mathrm{~b}$, bioreactor experiment, fermentation time $t=0-66 \mathrm{~h}$, in which lipid DCW values were $\approx 5 \% w / w$ ). After the two consecutive pulses with concentrated glycerol into the medium, lipid in yeast mass quantities somehow increased (to values $\approx 10-12 \% w / w$ ). This total lipid quantity increase occurred simultaneously with cell autolysis and substantial decrease in dry biomass concentration (Figure 4a), indicating once more, that despite cell autolysis, Y. lipolytica biomass was quite active at the late fermentation steps in the bioreactor culture. 


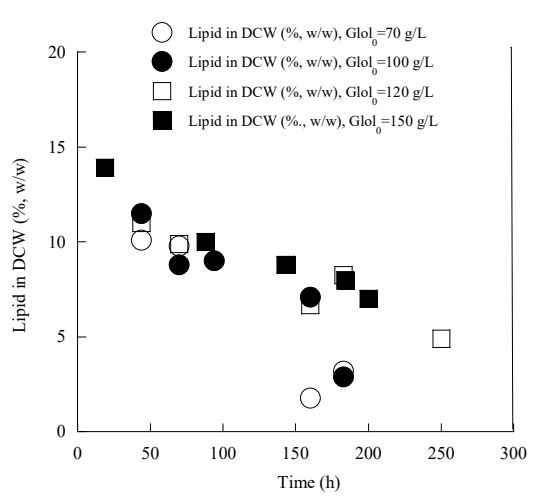

(a)

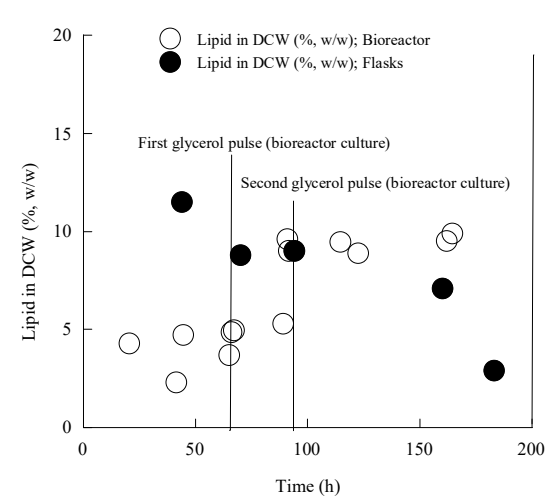

(b)

Figure 7. Kinetics of intra-cellular lipids produced per unit of dry cell weight $(\%, w / w)$ of Yarrowia lipolytica LMBF Y-46 during growth on pure glycerol, at various initial glycerol concentrations $\left(G y_{0}\right)$ imposed under nitrogen-limited conditions in shake-flask experiments (a) and shake-flask vs. pulsed fed-batch bioreactor experiments (in the latter case, for the shake-flask experiment, Gly $y_{0}$ concentration was $\approx 100 \mathrm{~g} / \mathrm{L})$. (b). Culture conditions as in Tables 1 and 3. Each point is the mean value of two independent determinations ( $\mathrm{SE} \leq 18 \%$ ).

Total cellular lipids were converted into their corresponding FAMEs, and cellular fatty acid (FA) composition analysis was performed for the late growth phase in the case of the shake-flask cultures, and throughout the culture, for the fed-batch bioreactor experiment (Table 6). In general, FA composition of total lipids of the strain LMBF Y-46 presented important similarities with those reported for various other $Y$. lipolytica strains cultivated in batch flask and bioreactor cultures, during growth on glycerol or similarly metabolized compounds, under nitrogen limitation $[8,16,18,19,21,22,38,40,49,53]$. Specifically, the yeast lipids were mainly composed of the FAs oleic (C18:1), palmitic (C16:0), palmitoleic (C16:1), stearic (C18:0) and linoleic (C18:2). No quantities of other poly-unsaturated FAs (i.e., $\alpha$-linolenic acid-C18:3) were detected inside the yeast lipids in accordance with the literature $[5,9,83]$. Small but not negligible quantities of lower (i.e., capric $-\mathrm{C} 10: 0$, lauric $-\mathrm{C} 12: 0$ and myristic $-\mathrm{C} 14: 0)$ or higher (i.e., arachidic $-\mathrm{C} 20: 0$, behenic $-\mathrm{C} 22: 0$ and lignoceric $-\mathrm{C} 24: 0)$ aliphatic chain saturated FAs have also been detected in the yeast lipids (Table 6). An interesting result that was observed through the cellular lipid analysis, referred to the fact that cellular lipids were somehow more saturated (mostly more rich in the FAs C16:0 and C18:0) in the shake-flask experiments compared with those obtained in the bioreactor cultures. In the latter case, cellular lipids were notably richer in the FAs C18:1 and C18:2. This could reflect the fact that bioreactor cultures were conducted under higher aeration compared with the flasks. Moreover, the first experimental point in the bioreactor trial that somehow presented higher concentrations of the cellular palmitic and stearic acids $(t=20.5 \mathrm{~h})$ compared with all other experimental points in this bioreactor experiment (see Table 6), could be attributed to the fact that at this very fermentation point, the DOT value (in $\%, v / v)$ was the lowest one in the relevant bioreactor trial (at $t=20.5 \mathrm{~h}$, DOT value into the reactor vessel was $\approx 20 \% v / v$, and thereafter it increased; see Figure $4 \mathrm{a}$ ). Similarly with this result, higher concentrations of the cellular FAs C16:0 and C18:0 have been noted in the beginning of other batch cultures performed by several Y. lipolytica strains on glucose or glycerol. These concentrations decreased as fermentations proceeded $[23,38,39,49]$. This could be attributed to the lower DOT values in these cultures at the early growth steps of the balanced growth phase of Y. lipolytica yeast. Finally, in accordance with the FA composition analysis results presented in the current investigation, strains of the oleaginous yeast $A$. curvatum had been cultured in air-lift bioreactor experiments, where somehow low DOT (and, thus, low OTR) values had been imposed, and while DCW production and cellular lipid biosynthesis were not seriously curtailed, storage lipids were noticeably enriched in the saturated FAs compared with the experiments presenting higher OTRs [89]. 
Table 6. Fatty acid composition of the cellular lipids produced by Yarrowia lipolytica LMBF Y-46 cultivated on glycerol in shake-flask, batch and fed-batch bioreactor experiments. Each experimental point presented is the mean value of two independent determinations. Culture conditions as in Tables 1 and 3.

\begin{tabular}{|c|c|c|c|c|c|c|c|c|c|c|}
\hline \multirow{2}{*}{$\begin{array}{c}\text { Culture Type/Time } \\
\text { Shake-Flasks }\end{array}$} & \multicolumn{10}{|c|}{ Fatty Acid Composition of Yeast Lipids $(\%, w / w)$} \\
\hline & $\leq \mathrm{C} 12: 0 *$ & C14:0 & C16:0 & C16:1 & C18:0 & C18:1 & C18:2 & C20:0 & $\geq \mathrm{C} 22: 0^{\$}$ & Other ${ }^{\times}$ \\
\hline$G l y_{0} \approx 70 \mathrm{~g} / \mathrm{L}, t \approx 180 \mathrm{~h}$ & $2.5 \pm 0.3$ & $2.3 \pm 0.4$ & $21.1 \pm 1.7$ & $5.1 \pm 0.6$ & $15.6 \pm 2.0$ & $30.2 \pm 3.5$ & $11.5 \pm 1.3$ & $0.8 \pm 0.1$ & $2.2 \pm 0.3$ & $8.7 \pm 0.9$ \\
\hline$G l y_{0} \approx 100 \mathrm{~g} / \mathrm{L}, t \approx 160 \mathrm{~h}$ & $0.8 \pm 0.1$ & $0.7 \pm 0.1$ & $22.2 \pm 3.5$ & $5.5 \pm 0.4$ & $18.5 \pm 2.4$ & $32.3 \pm 4.0$ & $12.2 \pm 2.0$ & $1.2 \pm 0.2$ & $2.5 \pm 0.4$ & $4.1 \pm 0.3$ \\
\hline$G l y_{0} \approx 100 \mathrm{~g} / \mathrm{L}, t \approx 180 \mathrm{~h}$ & $1.3 \pm 0.2$ & $0.9 \pm 0.2$ & $17.5 \pm 2.5$ & $3.6 \pm 0.5$ & $25.3 \pm 2.4$ & $28.4 \pm 4.1$ & $8.8 \pm 1.0$ & $5.9 \pm 1.1$ & $3.0 \pm 0.4$ & $5.3 \pm 0.6$ \\
\hline Gly $0 \approx 120 \mathrm{~g} / \mathrm{L}, t \approx 160 \mathrm{~h}$ & $1.8 \pm 0.3$ & $1.0 \pm 0.1$ & $19.9 \pm 2.0$ & $4.6 \pm 0.7$ & $18.9 \pm 3.0$ & $30.8 \pm 5.0$ & $9.0 \pm 1.5$ & $4.2 \pm 0.9$ & $2.0 \pm 0.3$ & $7.8 \pm 1.4$ \\
\hline Gly $y_{0} \approx 120 \mathrm{~g} / \mathrm{L}, t \approx 190 \mathrm{~h}$ & $0.2 \pm 0.1$ & $0.4 \pm 0.1$ & $21.7 \pm 2.4$ & $6.6 \pm 0.8$ & $15.9 \pm 2.5$ & $36.2 \pm 5.2$ & $12.8 \pm 2.0$ & $1.1 \pm 0.1$ & $2.9 \pm 0.5$ & $2.2 \pm 0.4$ \\
\hline Gly $y_{0} \approx 150 \mathrm{~g} / \mathrm{L}, t \approx 190 \mathrm{~h}$ & $3.9 \pm 0.2$ & $2.4 \pm 0.2$ & $19.5 \pm 1.9$ & $5.1 \pm 0.4$ & $18.0 \pm 3.2$ & $30.0 \pm 5.0$ & $10.7 \pm 1.8$ & $2.0 \pm 0.2$ & $2.0 \pm 0.4$ & $6.4 \pm 0.9$ \\
\hline Culture Type/Time & \multicolumn{10}{|c|}{ Fatty Acid Composition of Yeast Lipids $(\%, w / w)$} \\
\hline Bioreactor & $\leq \mathrm{C} 12: 0$ * & C14:0 & C16:0 & C16:1 & C18:0 & C18:1 & C18:2 & C20:0 & $\geq \mathrm{C} 22: 0^{\$}$ & Other ${ }^{x}$ \\
\hline$t=20.5 \mathrm{~h}$ & $1.9 \pm 0.4$ & $3.0 \pm 0.4$ & $21.1 \pm 2.5$ & $7.7 \pm 0.8$ & $17.0 \pm 1.8$ & $30.5 \pm 3.9$ & $17.7 \pm 2.6$ & - & - & $1.1 \pm 0.3$ \\
\hline$t=41.5 \mathrm{~h}$ & - & $1.2 \pm 0.2$ & $18.4 \pm 2.0$ & $6.8 \pm 0.9$ & $12.0 \pm 2.0$ & $37.3 \pm 4.0$ & $16.2 \pm 3.0$ & - & $3.0 \pm 0.4$ & $5.1 \pm 0.3$ \\
\hline$t=44.5 \mathrm{~h}$ & $1.5 \pm 0.4$ & $0.7 \pm 0.3$ & $16.5 \pm 2.0$ & $8.7 \pm 1.0$ & $7.7 \pm 1.0$ & $39.0 \pm 5.1$ & $15.4 \pm 2.9$ & $0.5 \pm 0.1$ & $2.6 \pm 0.4$ & $7.4 \pm 1.2$ \\
\hline$t=66.0 \mathrm{~h}$ & $2.5 \pm 0.2$ & $1.2 \pm 0.2$ & $16.4 \pm 2.1$ & $7.3 \pm 0.9$ & $9.2 \pm 1.4$ & $36.2 \pm 6.1$ & $14.9 \pm 3.0$ & $0.5 \pm 0.2$ & $2.2 \pm 0.4$ & $9.9 \pm 1.5$ \\
\hline$t=67.0 \mathrm{~h}$ & $1.7 \pm 0.1$ & $0.8 \pm 0.1$ & $16.3 \pm 2.2$ & $8.1 \pm 1.2$ & $8.1 \pm 1.3$ & $39.7 \pm 5.8$ & $16.7 \pm 3.1$ & $0.4 \pm 0.1$ & $2.8 \pm 0.3$ & $5.4 \pm 0.9$ \\
\hline$t=89.0 \mathrm{~h}$ & $0.7 \pm 0.1$ & $0.6 \pm 0.1$ & $16.7 \pm 2.3$ & $9.0 \pm 1.4$ & $8.1 \pm 1.6$ & $40.3 \pm 6.0$ & $16.1 \pm 3.2$ & $0.4 \pm 0.1$ & $2.7 \pm 0.3$ & $5.4 \pm 1$ \\
\hline$t=91.0 \mathrm{~h}$ & $2.2 \pm 0.3$ & $1.1 \pm 0.2$ & $17.0 \pm 1.9$ & $8.4 \pm 1.7$ & $8.4 \pm 1.5$ & $37.4 \pm 5.1$ & $16.2 \pm 3.0$ & $0.3 \pm 0.1$ & $1.5 \pm 0.2$ & $7.5 \pm 1.3$ \\
\hline$t=164.0 \mathrm{~h}$ & $1.1 \pm 0.2$ & $0.8 \pm 0.4$ & $15.0 \pm 1.9$ & $9.5 \pm 1.5$ & $6.0 \pm 1.0$ & $43.0 \pm 4.4$ & $17.9 \pm 3.1$ & $0.8 \pm 0.1$ & $1.9 \pm 0.3$ & $4.0 \pm 0.8$ \\
\hline
\end{tabular}

${ }^{*}: \mathrm{C} 12: 0$ and $\mathrm{C} 10: 0 ;{ }^{\$}: \mathrm{C} 22: 0$ and C24:0; ${ }^{\times}: \mathrm{C} 8: 0, \mathrm{C} 11: 00, \mathrm{C} 20: 1, \mathrm{C} 17: 0, \mathrm{C} 15: 0$. 


\section{Concluding Remarks}

Y. lipolytica LMBF Y-46 significantly resisted high Gly concentrations in the medium (up to $\approx 150 \mathrm{~g} / \mathrm{L}$ ), demonstrating simultaneously remarkable DCW synthesis and glycerol uptake during shake-flask cultures. Although medium $\mathrm{pH}$ remained $\geq 4.5$, cultures were accompanied by an interesting production of polyols $(\mathrm{Pol} \approx 52 \mathrm{~g} / \mathrm{L})$. In aerated bioreactor experiments, a metabolic shift towards citric acid production was observed, while simultaneously insignificant polyol quantities were synthesized. A maximum total citric acid quantity of $\approx 102 \mathrm{~g} / \mathrm{L}$, one of the highest in the literature for wild-type $Y$. lipolytica strains, was recorded in a successful fed-batch experiment with glycerol employed as the substrate. The metabolic transition from the biosynthesis of polyols (shake-flask trials) towards citric acid (bioreactor trials) was attributed to the higher oxygen saturation in the medium that occurred in the latter cas0e. In the bioreactor experiments, cellular lipids containing higher concentrations of unsaturated FAs were noted. The current study therefore, provided strong evidence that a new wild-type food-derived $Y$. lipolytica strain can successfully be implicated as a microbial cell factory in order to convert glycerol, an abundant low-cost material, into added-value metabolic compounds of importance for the food and chemical industries.

Author Contributions: Conceptualization, S.P.; Data curation, P.D. and N.G.S.; Funding acquisition, I.C.; Investigation, P.D., N.G.S. and E.R.; Methodology, F.B. and E.L.; Project administration, I.C.; Supervision, E.R. All authors have read and agreed to the published version of the manuscript.

Funding: The current investigation was financially supported by: (1) The project entitled "Adding value to biodiesel-derived crude glycerol with the use of Chemical and Microbial Technology" (Acronym: Addvalue2glycerol, project code T1E $\Delta$ K-03002) financed by the Ministry of National Education and Religious Affairs, Greece (project action: "Investigate-Create-Innovate 2014-2020, Intervention II"); (2) The project "Impact Biomolecules" of the "Lorraine Université d'Excellence" (PIA-ANR).

Conflicts of Interest: The authors have declared no conflict of interest.

\section{References}

1. Chatzifragkou, A.; Papanikolaou, S. Effect of impurities in biodiesel-derived waste glycerol on the performance and feasibility of biotechnological processes. Appl. Microbiol. Biotechnol. 2012, 95, 13-27. [CrossRef] [PubMed]

2. Rywińska, A.; Juszczyk, P.; Wojtatowicz, M.; Robak, M.; Lazar, Z.; Tomaszewska, L.; Rymowicz, W. Glycerol as a promising substrate for Yarrowia lipolytica biotechnological applications. Biomass Bioenergy 2013, 48, 148-166. [CrossRef]

3. Russmayer, H.; Egermeier, M.; Kalemasi, D.; Sauer, M. Spotlight on biodiversity of microbial cell factories for glycerol conversion. Biotechnol. Adv. 2019, 37, 107395. [CrossRef]

4. Rzechonek, D.A.; Dobrowolski, A.; Rymowicz, W.; Mirończuk, A.M. Recent advances in biological production of erythritol. Crit. Rev. Biotechnol. 2018, 38, 620-633. [CrossRef] [PubMed]

5. Patel, A.; Karageorgou, D.; Rova, E.; Katapodis, P.; Rova, U.; Christakopoulos, P.; Matsakas, L. An overview of potential oleaginous microorganisms and their role in biodiesel and omega-3 fatty acid-based industries. Microorganisms 2020, 8, 434. [CrossRef] [PubMed]

6. Yazdani, S.S.; Gonzalez, R. Anaerobic fermentation of glycerol: A path to economic viability for the biofuels industry. Curr. Opin. Biotechnol. 2007, 18, 213-219. [CrossRef]

7. Clomburg, J.M.; Gonzalez, R. Anaerobic fermentation of glycerol: A platform for renewable fuels and chemicals. Trend Biotechnol. 2013, 31, 20-28. [CrossRef]

8. Papanikolaou, S.; Fakas, S.; Fick, M.; Chevalot, I.; Galiotou-Panayotou, M.; Komaitis, M.; Marc, I.; Aggelis, G. Biotechnological valorisation of raw glycerol discharged after bio-diesel (fatty acid methyl-esters) manufacturing process: Production of 1,3-propanediol, citric acid and single cell oil. Biomass Bioenergy 2008, 32, 60-71. [CrossRef]

9. Kothri, M.; Mavrommati, M.; Elazzazy, A.M.; Baeshen, M.N.; Moussa, T.A.; Aggelis, G. Microbial sources of polyunsaturated fatty acids (PUFAs) and the prospect of organic residues and wastes as growth media for PUFA-producing microorganisms. FEMS Microbiol. Lett. 2020, 367, fnaa028. [CrossRef]

10. Fickers, P.; Cheng, H.; Lin, C.S.K. Sugar alcohols and organic acids synthesis in Yarrowia lipolytica: Where are we? Microorganisms 2020, 8, 574. [CrossRef]

11. Bankar, V.A.; Kumar, R.A.; Zinjarde, S.S. Environmental and industrial applications of Yarrowia lipolytica. Appl. Microbiol. Biotechnol. 2009, 84, 847-865. [CrossRef] [PubMed] 
12. Zinjarde, S.S.; Apte, M.; Mohite, P. Yarrowia lipolytica and pollutants: Interactions and applications. Biotechnol. Adv. 2014, 32, 920-933. [CrossRef] [PubMed]

13. Carly, F.; Fickers, P. Erythritol production by yeasts: A snapshot of current knowledge. Yeast 2018, 35, 455-463. [CrossRef] [PubMed]

14. Timumi, A.; Guillouet, S.E.; Molina-Jouve, C.; Fillaudeau, L.; Gorret, N. Impacts of environmental conditions on product formation and morphology of Yarrowia lipolytica. Appl. Microbiol. Biotechnol. 2018, 102, 3831-3848. [CrossRef]

15. Egermeier, M.; Sauer, M.; Marx, H. Golden gate-based metabolic engineering strategy for wild-type strains of Yarrowia lipolytica. FEMS Microbiol. Lett. 2019, 366, fnz022. [CrossRef]

16. Diamantopoulou, P.; Filippousi, R.; Antoniou, D.; Varfi, E.; Xenopoulos, E.; Sarris, D.; Papanikolaou, S. Production of added-value microbial metabolites during growth of yeast strains on media composed of biodiesel-derived crude glycerol and glycerol/xylose blends. FEMS Microbiol. Lett. 2020, 367, fnaa063. [CrossRef]

17. Tryfinopoulou, P.; Tsakalidou, E.; Nychas, G.J.E. Characterization of Pseudomonas spp. associated with spoilage of gilt-head sea-bream stored under various conditions. Appl. Environ. Microbiol. 2002, 68, 65-72. [CrossRef] [PubMed]

18. Papanikolaou, S.; Kampisopoulou, E.; Blanchard, F.; Rondags, E.; Gardeli, C.; Koutinas, A.A.; Chevalot, I.; Aggelis, G. Production of secondary metabolites through glycerol fermentation under carbon-excess conditions by the yeasts Yarrowia lipolytica and Rhodosporidium toruloides. Eur. J. Lipid Sci. Technol. 2017, 119, 1600507. [CrossRef]

19. Papanikolaou, S.; Galiotou-Panayotou, M.; Fakas, S.; Komaitis, M.; Aggelis, G. Citric acid production by Yarrowia lipolytica cultivated on olive-mill wastewater-based media. Bioresour. Technol. 2008, 99, 2419-2428. [CrossRef]

20. Palaiogeorgou, A.M.; Papanikolaou, S.; de Castro, A.M.; Freire, D.M.G.; Kookos, I.K.; Koutinas, A.A. A newly isolated Enterobacter sp. strain produces 2,3-butanediol during its cultivation on low-cost carbohydrate-based substrates. FEMS Microbiol. Lett. 2019, 366, fny280. [CrossRef]

21. Papanikolaou, S.; Rontou, M.; Belka, A.; Athenaki, M.; Gardeli, C.; Mallouchos, A.; Kalantzi, O.; Koutinas, A.A.; Kookos, I.K.; Zeng, A.P.; et al. Conversion of biodiesel-derived glycerol into biotechnological products of industrial significance by yeast and fungal strains. Eng. Life Sci. 2017, 17, 262-281. [CrossRef] [PubMed]

22. Chatzifragkou, A.; Makri, A.; Belka, A.; Bellou, S.; Mavrou, M.; Mastoridou, M.; Mystrioti, P.; Onjaro, G.; Aggelis, G.; Papanikolaou, S. Biotechnological conversions of biodiesel derived waste glycerol by yeast and fungal species. Energy 2011, 36, 1097-1108. [CrossRef]

23. Papanikolaou, S.; Muniglia, L.; Chevalot, I.; Aggelis, G.; Marc, I. Yarrowia lipolytica as a potential producer of citric acid from raw glycerol. J. Appl. Microbiol. 2002, 92, 737-744. [CrossRef]

24. Gardeli, C.; Athenaki, M.; Xenopoulos, E.; Mallouchos, A.; Koutinas, A.A.; Aggelis, G.; Papanikolaou, S. Lipid production and characterization by Mortierella (Umbelopsis) isabellina cultivated on lignocellulosic sugars. J. Appl. Microbiol. 2017, 123, 1461-1477. [CrossRef]

25. Papanikolaou, S.; Sarantou, S.; Komaitis, M.; Aggelis, G. Repression of reserve lipid turnover in Cunninghamella echinulata and Mortierella isabellina cultivated in multiple-limited media. J. Appl. Microbiol. 2004, 97, 867-874. [CrossRef] [PubMed]

26. Bellou, S.; Moustogianni, A.; Makri, A.; Aggelis, G. Lipids containing polyunsaturated fatty acids synthesized by Zygomycetes grown on glycerol. App. Biochem. Biotechnol. 2012, 166, 146-158. [CrossRef]

27. Metsoviti, M.; Paraskevaidi, K.; Koutinas, A.; Zeng, A.P.; Papanikolaou, S. Production of 1,3-propanediol, 2,3-butanediol and ethanol by a newly isolated Klebsiella oxytoca strain growing on biodiesel-derived glycerol based media. Proc. Biochem. 2012, 47, 1872-1882. [CrossRef]

28. Chatzifragkou, A.; Dietz, D.; Komaitis, M.; Zeng, A.P.; Papanikolaou, S. Effect of biodiesel-derived waste glycerol impurities on biomass and 1,3-propanediol production of Clostridium butyricum VPI 1718. Biotechnol. Bioeng. 2010, 107, 76-84. [CrossRef]

29. Tomaszewska, L.; Rywińska, A.; Gładkowski, W. Production of erythritol and mannitol by Yarrowia lipolytica yeast in media containing glycerol. J. Ind. Microbiol. Biotechnol. 2012, 39, 1333-1343. [CrossRef]

30. Venkataramanan, K.P.; Boatman, J.J.; Kurniawan, Y.; Taconi, K.A.; Bothun, G.D.; Scholz, C. Impact of impurities in biodiesel-derived crude glycerol on the fermentation by Clostridium pasteurianum ATCC 6013. Appl. Microbiol. Biotechnol. 2012, 93, 1325-1335. [CrossRef] 
31. Mirończuk, A.M.; Furgala, I.; Rakicka, M.; Rymowicz, W. Enhanced production of erythritol by Yarrowia lipolytica on gycerol in repeated batch cultures. J. Ind. Microbiol. Biotechnol. 2014, 41, 57-64. [CrossRef] [PubMed]

32. Dobrowolski, A.; Mituła, P.; Rymowicz, W.; Mirończuk, A.M. Efficient conversion of crude glycerol from various industrial wastes into single cell oil by yeast Yarrowia lipolytica. Bioresour. Technol. 2016, 207, 237-243. [CrossRef] [PubMed]

33. Uprety, B.K.; Dalli, S.S.; Rakshit, S.K. Bioconversion of crude glycerol to microbial lipid using a robust oleaginous yeast Rhodosporidium toruloides ATCC 10788 capable of growing in the presence of impurities. Energy Conv. Manag. 2017, 135, 117-128. [CrossRef]

34. Chebbi, H.; Leiva-Candia, D.; Carmona-Cabello, M.; Jaouani, A.; Dorado, M.P. Biodiesel production from microbial oil provided by oleaginous yeasts from olive oil mill wastewater growing on industrial glycerol. Ind. Crop. Prod. 2019, 139, 111535. [CrossRef]

35. Carly, F.; Vandermies, M.; Telek, S.; Steels, S.; Thomas, S.; Nicaud, J.M.; Fickers, P. Enhancing erythritol productivity in Yarrowia lipolytica using metabolic engineering. Metab. Eng. 2017, 42, 19-24. [CrossRef]

36. Egermeier, M.; Russmayer, H.; Sauer, M.; Marx, H. Metabolic flexibility of Yarrowia lipolytica growing on glycerol. Front. Microbiol. 2017, 8, 49. [CrossRef]

37. Filippoussi, R.; Antoniou, D.; Tryfinopoulou, P.; Nisiotou, A.A.; Nychas, G.J.; Koutinas, A.A.; Papanikolaou, S. Isolation, identification and screening of yeasts towards their ability to assimilate biodiesel-derived crude glycerol: Microbial production of polyols, endopolysaccharides and lipid. J. Appl. Microbiol. 2019, 127, 1080-1100. [CrossRef]

38. André, A.; Chatzifragkou, A.; Diamantopoulou, P.; Sarris, D.; Philippoussis, A.; Galiotou-Panayotou, M.; Komaitis, M.; Papanikolaou, S. Biotechnological conversions of bio-diesel derived crude glycerol by Yarrowia lipolytica strains. Eng. Life Sci. 2009, 9, 468-478. [CrossRef]

39. Makri, A.; Fakas, S.; Aggelis, G. Metabolic activities of biotechnological interest in Yarrowia lipolytica grown on glycerol in repeated batch cultures. Bioresour. Technol. 2010, 101, 2351-2358. [CrossRef]

40. Papanikolaou, S.; Beopoulos, A.; Koletti, A.; Thevenieau, F.; Koutinas, A.A.; Nicaud, J.M.; Aggelis, G. Importance of the methyl-citrate cycle on glycerol metabolism in the yeast Yarrowia lipolytica. J. Biotechnol. 2013, 168, 303-314. [CrossRef]

41. Evans, C.T.; Ratledge, C. Phosphofructokinase and its regulation of the flux of carbon from glucose to lipid in the oleaginous yeast Rhodosporidium toruloides. J. Gen. Microbiol 1984, 130, 3251-3264.

42. Park, W.S.; Murphy, P.A.; Glatz, B.A. Lipid metabolism and cell composition of the oleaginous yeast Apiotrichum curvatum grown at different carbon to nitrogen ratios. Can. J. Microbiol. 1990, 36, 318-326. [CrossRef] [PubMed]

43. Daskalaki, A.; Perdikouli, D.; Aggeli, D.; Aggelis, G. Laboratory evolution strategies for improving lipid accumulation in Yarrowia lipolytica. Appl. Microbiol. Biotechnol. 2019, 103, 8585-8596. [CrossRef]

44. Rymowicz, W.; Rywińska, A.; Zarowska, B.; Juszczyk, P. Citric acid production from raw glycerol by acetate mutants of Yarrowia lipolytica. Chem. Pap. 2006, 60, 391-394. [CrossRef]

45. Rymowicz, W.; Rywińska, A.; Gladkowski, W. Simultaneous production of citric acid and erythritol from crude glycerol by Yarrowia lipolytica Wratislavia K1. Chem. Pap. 2008, 62, 239-246. [CrossRef]

46. Rymowicz, W.; Rywińska, A.; Marcinkiewicz, M. High-yield production of erythritol from raw glycerol in fed-batch cultures of Yarrowia lipolytica. Biotechnol. Lett. 2009, 31, 377-380. [CrossRef]

47. Rymowicz, W.; Fatykhova, A.R.; Kamzolova, S.V.; Rywińska, A.; Morgunov, I.G. Citric acid production from glycerol-containing waste of biodiesel industry by Yarrowia lipolytica in batch, repeated batch, and cell recycle regimes. Appl. Microbiol. Biotechnol. 2010, 87, 971-979. [CrossRef]

48. Tomaszewska, L.; Rakicka, M.; Rymowicz, W.; Rywińska, A. A comparative study on glycerol metabolism to erythritol and citric acid in Yarrowia lipolytica yeast cells. FEMS Yeast Res. 2014, 14, 966-976. [CrossRef] [PubMed]

49. Sarris, D.; Sampani, Z.; Rapti, A.; Papanikolaou, S. Valorization of crude glycerol, residue deriving from biodiesel-production process, with the use of wild-type new isolated Yarrowia lipolytica strains: Production of metabolites with pharmaceutical and biotechnological interest. Curr. Pharm. Biotechnol. 2019, 20, 881-894. [CrossRef]

50. Mirończuk, A.M.; Dobrowolski, A.; Rakicka, M.; Rywińska, A.; Rymowicz, W. Newly isolated mutant of Yarrowia lipolytica MK1 as a proper hostfor efficient erythritol biosynthesis from glycerol. Proc. Biochem. 2015, 50, 61-68. [CrossRef] 
51. Rakicka, M.; Kieron, A.; Hapeta, P.; Neuvéglise, C.; Lazar, Z. Sweet and sour potential of yeast from the Yarrowia clade. Biomass Bioenergy 2016, 92, 48-54. [CrossRef]

52. Rakicka, M.; Biegalska, A.; Rymowicz, W.; Dobrowolski, A.; Mirończuk, A.M. Polyol production from waste materials by genetically modified Yarrowia lipolytica. Bioresour. Technol. 2017, 243, 393-399. [CrossRef]

53. Sarris, D.; Rapti, A.; Papafotis, N.; Koutinas, A.A.; Papanikolaou, S. Production of added-value chemical compounds through bioconversions of olive-mill wastewaters blended with crude glycerol by a Yarrowia lipolytica strain. Molecules 2019, 24, 222. [CrossRef] [PubMed]

54. Liu, X.; Yu, X.; Wang, Z.; Xia, J.; Yan, Y.; Hu, L.; Wang, X.; Xu, J.; He, A.; Zhao, P. Enhanced erythritol production by a Snf1-deficient Yarrowia lipolytica strain under nitrogen-enrichedfermentation condition. Food Bioprod. Proc. 2020, 119, 306-316. [CrossRef]

55. Rywińska, A.; Rymowicz, W.; Zarowska, B.; Skrzypiński, A. Comparison of citric acid production from glycerol and glucose by different strains of Yarrowia lipolytica. World J. Microbiol. Biotechnol. 2010, 26, 1217-1224. [CrossRef] [PubMed]

56. Kamzolova, S.V.; Morgunov, I.; Aurich, A.; Perevoznikova, O.A.; Shishkanova, N.V.; Stottmeister, U.; Finogenova, T.V. Lipase secretion and citric acid production in Yarrowia lipolytica yeast grown on animal and vegetable fat. Food Technol. Biotechnol. 2005, 43, 113-122.

57. Förster, A.; Aurich, A.; Mauersberger, S.; Barth, G. Citric acid production from sucrose using a recombinant strain of the yeast Yarrowia lipolytica. Appl. Microbiol. Biotechnol. 2007, 75, 1409-1417.

58. Rywińska, A.; Rymowicz, W. Citric acid production from raw glycerol by Yarrowia lipolytica Wratislavia 1.31. In Microbial Conversions of Raw Glycerol; Aggelis, G., Ed.; Nova Science Publishers Inc.: New York, NY, USA, 2009; pp. 19-30.

59. Morgunov, I.G.; Kamzolova, S.V.; Lunina, J.N. The citric acid production from raw glycerol by Yarrowia lipolytica yeast and its regulation. Appl. Microbiol. Biotechnol. 2013, 97, 7387-7397. [CrossRef]

60. Rywińska, A.; Juszczyk, P.; Wojtatowicz, M.; Rymowicz, W. Chemostat study of citric acid production from glycerol by Yarrowia lipolytica. J. Biotechnol. 2011, 152, 54-57. [CrossRef]

61. Kamzolova, S.V.; Fatykhova, A.R.; Dedyukhina, E.G.; Anastassiadis, S.G.; Golovchenko, N.P.; Morgunov, I.G. Citric acid production by yeast grown on glycerol-containing waste from biodiesel industry. Food Technol. Biotechnol. 2011, 49, 65-74.

62. Carsanba, E.; Papanikolaou, S.; Fickers, P.; Erten, H. Screening various Yarrowia lipolytica strains for citric acid production. Yeast 2019, 36, 319-327. [CrossRef] [PubMed]

63. Rzechonek, D.A.; Dobrowolski, A.; Rymowicz, W.; Mirończuk, A.M. Aseptic production of citric and isocitric acid from crude glycerol by genetically modified Yarrowia lipolytica. Bioresour. Technol. 2019, 38, 340-344. [CrossRef] [PubMed]

64. Ferreira, P.; Lopes, M.; Mota, M.; Belo, I. Oxygen transfer rate and $\mathrm{pH}$ as major operating parameters of citric acid production from glycerol by Yarrowia lipolytica W29 and CBS 2073. Chem. Pap. 2016, 70, 869-876. [CrossRef]

65. Ferreira, P.; Lopes, M.; Mota, M.; Belo, I. Oxygen mass transfer impact on citric acid production by Yarrowia lipolytica from crude glycerol. Biochem. Eng. J. 2016, 110, 35-42. [CrossRef]

66. Rywińska, A.; Musiał, I.; Rymowicz, W.; Żarowska, B.; Boruczkowski, T. Effect of agitation and aeration on the citric acid production by Yarrowia lipolytica grown on glycerol. Prep. Biochem. Biotechnol. 2012, 42, 279-291. [CrossRef]

67. Tan, M.-J.; Chen, X.; Wang, Y.-K.; Liu, G.-L.; Chi, Z.-M. Enhanced citric acid production by a yeast Yarrowia lipolytica over-expressing a pyruvate carboxylase gene. Bioprocess. Biosyst. Eng. 2016, 39, 1289-1296. [CrossRef]

68. Moresi, C. Effect of glucose concentration on citric acid production by Yarrowia lipolytica-Kinetics of the trophophase, citrate lag phase and idiophase. J. Chem. Technol. Biotechnol. 1994, 60, 387-395. [CrossRef]

69. Klasson, T.K.; Clausen, E.C.; Gaddy, J.L. Continuous fermentation for the production of citric acid from glucose. Appl. Biochem. Biotechnol. 1989, 21, 491-509. [CrossRef]

70. Rane, K.; Sims, K. Production of citric acid by Candida lipolytica Y 1095: Effect of glucose concentration on yield and productivity. Enz. Microb. Technol. 1993, 15, 646-651. [CrossRef]

71. Kamzolova, S.V.; Shishkanova, N.; Morgunov, I.G.; Finogenova, T.V. Oxygen requirements for growth and citric acid production of Yarrowia lipolytica. FEMS Yeast Res. 2003, 3, 217-222. [CrossRef] 
72. Rywińska, A.; Rymowicz, W.; Marcinkiewicz, M. Valorization of raw glycerol for citric acid production by Yarrowia lipolytica yeast. Electron. J. Biotechnol. 2010, 13, 4. [CrossRef]

73. Rywińska, A.; Rymowicz, W. High-yield production of citric acid by Yarrowia lipolytica on glycerol in repeated-batch bioreactors. J. Ind. Microbiol. Biotechnol. 2010, 37, 431-435. [CrossRef] [PubMed]

74. Kamzolova, S.V.; Lunina, J.N.; Morgunov, I.G. Biochemistry of citric acid production from rapeseed oil by Yarrowia lipolytica yeast. J. Am. Oil Chem. Soc. 2011, 88, 1965-1976. [CrossRef]

75. Liu, X.Y.; Chi, Z.; Liu, G.L.; Madzak, C.; Chi, Z.M. Both decrease in ACL1 gene expression and increase in ICL1 gene expression in marine-derived yeast Yarrowia lipolytica expressing INU1 gene enhance citric acid production from inulin. Mar. Biotechnol. 2013, 15, 26-36. [CrossRef] [PubMed]

76. Kamzolova, S.V.; Morgunov, I.G. Metabolic peculiarities of the citric acid overproduction from glucose in yeasts Yarrowia lipolytica. Bioresour. Technol. 2017, 243, 433-440. [CrossRef]

77. Morgunov, I.G.; Kamzolova, S.V.; Lunina, J.N. Citric acid production by Yarrowia lipolytica yeast on different renewable raw materials. Fermentation 2018, 4, 36. [CrossRef]

78. Diamantopoulou, P.; Stoforos, N.G.; Xenopoulos, E.; Sarris, D.; Psarianos, D.; Philippoussis, A.; Papanikolaou, S. Lipid production by Cryptococcus curvatus growing on commercial xylose and subsequent valorization of fermentation waste-waters for the production of edible and medicinal mushrooms. Biochem. Eng. J. 2020, 162, 107706. [CrossRef]

79. Sarris, D.; Stoforos, N.G.; Mallouchos, A.; Kookos, I.K.; Koutinas, A.A.; Aggelis, G.; Papanikolaou, S. Production of added-value metabolites by Yarrowia lipolytica growing in olive mill wastewater-based media under aseptic and non-aseptic conditions. Eng. Life Sci. 2017, 17, 695-709. [CrossRef]

80. Aggelis, G.; Sourdis, J. Prediction of lipid accumulation-degradation in oleaginous micro-organisms growing on vegetable oils. Antonie Leeuwenhoek 1997, 72, 159-165. [CrossRef]

81. Galiotou-Panayotou, M.; Kalantzi, O.; Aggelis, G. Modelling of simultaneous production of polygalacturonase and exopolysaccharide by Aureobasidium pullulans ATHUM 2915. Antonie Leeuwenhoek 1998, 73, $155-162$. [CrossRef]

82. Papanikolaou, S.; Aggelis, G. Modelling aspects of the biotechnological valorization of raw glycerol: Production of citric acid by Yarrowia lipolytica and 1,3-propanediol by Clostridium butyricum. J. Chem. Technol. Biotechnol. 2003, 78, 542-547. [CrossRef]

83. Papanikolaou, S.; Aggelis, G. Sources of microbial oils with emphasis to Mortierella (Umbelopsis) isabellina fungus. World J. Microbiol. Biotechnol. 2019, 35, 63. [CrossRef]

84. Ochoa-Estopier, A.; Guillouet, S.E. D-stat culture for studying the metabolic shifts from oxidative metabolism to lipid accumulation and citric acid production in Yarrowia lipolytica. J. Biotechnol. 2014, 170, 35-41. [CrossRef] [PubMed]

85. Bellou, S.; Triantaphyllidou, I.E.; Mizerakis, P.; Aggelis, G. High lipid accumulation in Yarrowia lipolytica cultivated under double limitation of nitrogen and magnesium. J. Biotechnol. 2016, 234, 116-126. [CrossRef]

86. Beopoulos, A.; Haddouche, R.; Kabran, P.; Dulermo, T.; Chardot, T.; Nicaud, J.M. Identification and characterization of DGA2, an acyltransferase of the DGAT1 acyl-CoA:diacylglycerol acyltransferase family in the oleaginous yeast Yarrowia lipolytica. New insights into the storage lipid metabolism of oleaginous yeasts. Appl. Microbiol. Biotechnol. 2012, 93, 1523-1537. [CrossRef] [PubMed]

87. Tai, M.; Stephanopoulos, G. Engineering the push and pull of lipid biosynthesis in oleaginous yeast Yarrowia lipolytica for biofuel production. Metab. Eng. 2013, 15, 1-9. [CrossRef] [PubMed]

88. Qiao, K.; Imam Abidi, S.H.; Liu, H.; Zhang, H.; Chakraborty, S.; Watson, N.; Ajikumar, P.K.; Stephanopoulos, G. Engineering lipid overproduction in the oleaginous yeast Yarrowia lipolytica. Metab. Eng. 2015, 29, 56-65. [CrossRef]

89. Davies, R.J.; Holdsworth, J.E.; Reader, S.L. The effect of low oxygen uptake rate on the fatty acid profile of the oleaginous yeast Apiotrichum curvatum. Appl. Microbiol. Biotechnol. 1990, 33, 569-573. [CrossRef]

Publisher's Note: MDPI stays neutral with regard to jurisdictional claims in published maps and institutional affiliations. 